\title{
Tentative detection of ethylene glycol toward W51/e2 and G34.3+0.2
}

\author{
J. M. Lykke ${ }^{1}$, C. Favre ${ }^{2}$, E. A. Bergin ${ }^{2}$, and J. K. Jørgensen ${ }^{1}$ \\ ${ }^{1}$ Centre for Star and Planet Formation, Niels Bohr Institute \& Natural History Museum of Denmark, University of Copenhagen, \\ Øster Voldgade 5-7, 1350 Copenhagen K., Denmark \\ e-mail: juliemarialykke@gmail.com \\ 2 Department of Astronomy, University of Michigan, 500 Church Street, Ann Arbor, MI 48109, USA
}

Received 30 March 2015 / Accepted 4 July 2015

\begin{abstract}
Context. With only a few low- and high-mass star-formation regions studied in detail so far, it is unclear what role the enviroment plays in complex molecule formation. In this light, a comparison of relative abundances of related species between sources might be useful for explaining any observed differences.

Aims. We seek to measure the relative abundance between three important complex organic molecules, ethylene glycol $\left(\left(\mathrm{CH}_{2} \mathrm{OH}\right)_{2}\right)$, glycolaldehyde $\left(\mathrm{CH}_{2} \mathrm{OHCHO}\right)$ and methyl formate $\left(\mathrm{HCOOCH}_{3}\right)$, toward high-mass protostars and thereby provide additional constraints on their formation pathways.

Methods. We use IRAM $30 \mathrm{~m}$ single-dish observations of the three species toward two high-mass star-forming regions - W51/e2 and G34.3+0.2 - and report a tentative detection of $\left(\mathrm{CH}_{2} \mathrm{OH}\right)_{2}$ toward both sources.

Results. Assuming that $\left(\mathrm{CH}_{2} \mathrm{OH}\right)_{2}, \mathrm{CH}_{2} \mathrm{OHCHO}$, and $\mathrm{HCOOCH}_{3}$ spatially coexist, relative abundance ratios, $\mathrm{HCOOCH}_{3} /\left(\mathrm{CH}_{2} \mathrm{OH}\right)_{2}$, of 31 and 35 are derived for $\mathrm{G} 34.3+0.2$ and $\mathrm{W} 51 / \mathrm{e} 2$, respectively. $\mathrm{CH}_{2} \mathrm{OHCHO}$ is not detected, but the data provide lower limits to the $\mathrm{HCOOCH}_{3} / \mathrm{CH}_{2} \mathrm{OHCHO}$ abundance ratios of $\geq 193$ for $\mathrm{G} 34.3+0.2$ and $\geq 550$ for W51/e2. A comparison of these results to measurements from various sources in the literature indicates that the source luminosities may be correlated with the $\mathrm{HCOOCH}_{3} /\left(\mathrm{CH}_{2} \mathrm{OH}\right)_{2}$ and $\mathrm{HCOOCH}_{3} / \mathrm{CH}_{2} \mathrm{OHCHO}$ ratios. This apparent correlation may be a consequence of the relative time scales each source spend at different temperature ranges in their evolution. Furthermore, we obtain lower limits to the ratio of $\left(\mathrm{CH}_{2} \mathrm{OH}\right)_{2} / \mathrm{CH}_{2} \mathrm{OHCHO}$ for $\mathrm{G} 34.3+0.2(\geq 6)$ and W51/e2 $(\geq 16)$. This result confirms that a high $\left(\mathrm{CH}_{2} \mathrm{OH}\right)_{2} / \mathrm{CH}_{2} \mathrm{OHCHO}$ abundance ratio is not a specific property of comets, as previously speculated.
\end{abstract}

Key words. ISM: molecules - ISM: abundances - ISM: individual objects: W51/e2 - methods: observational - astrochemistry ISM: individual objects: G34.3+0.2

\section{Introduction}

How complex organic - and potentially prebiotic - molecules are formed in regions of low- and high-mass star formation remains a central question in astrochemistry. To date there has been no consensus about how complex organic molecules (COMs hereafter) form in dense regions of the interstellar medium, despite the increasing number of detections (e.g., Herbst \& van Dishoeck 2009). One promising suggestion was that warm gas phase chemistry, following evaporation of simple ices, could be a primary formation pathway (e.g., Millar et al. 1991; Charnley et al. 1992). However, more recent laboratory experiments and chemical modeling has shown that this mechanism is not effective enough to account for the observed abundances (e.g., Geppert et al. 2006). An alternative formation mechanism involves UV induced radicals. Garrod et al. (2008) propose that, during the warm up phase, radicals can migrate on the grains surfaces and form complex species that

\footnotetext{
* Based on observations carried out with the IRAM 30 m telescope.

$\star \star$ The reduced spectra (FITS files) are only available at the CDS via anonymous ftp to cdsarc.u-strasbg. fr $(130.79 .128 .5)$ or via http://cdsarc.u-strasbg.fr/viz-bin/qcat?J/A+A/582/A64 $\star \star \star$ Appendices are available in electronic form at http://www . aanda.org
}

are then released into the gas phase at higher temperatures. The initial ice composition and the amount of UV radiation have also proved to play an important part in the formation process (Öberg et al. 2009). To determine the formation pathway of COMs, it is useful to determine abundance ratios between different related species because these ratios, in comparison with the predicted abundance ratios from chemical models, can provide constraints on the formation processes. Indeed, variations in the abundance profiles can reflect the physical and chemical conditions that are occurring. It is therefore important to observe these species in different environments.

Some of the simplest species in this context include the oxygen-bearing COMs associated to glycolaldehyde, $\mathrm{CH}_{2} \mathrm{OHCHO}$, including its isomer methyl formate $\left(\mathrm{HCOOCH}_{3}\right.$ or $\mathrm{CH}_{3} \mathrm{OCHO}$ ) and the reduced alcohol version of $\mathrm{CH}_{2} \mathrm{OHCHO}$, ethylene glycol, $\left(\mathrm{CH}_{2} \mathrm{OH}\right)_{2}$ (also commonly known as antifreeze). By constraining the relative abundances of these species in different environments the hope is to be able to explore, for instance, the importance of initial chemical conditions, temperature and irradiation in the formation for comparison, such as for laboratory experiments (e.g., Öberg et al. 2009) and as input for sophisticated chemical models (e.g., Garrod et al. 2008). For example, in their laboratory experiments Öberg et al. (2009) show that the relative abundances of $\mathrm{HCOOCH}_{3}$ to $\mathrm{CH}_{2} \mathrm{OHCHO}$ and 
$\left(\mathrm{CH}_{2} \mathrm{OH}\right)_{2}$ strongly depend on both the ice temperature and exact ice composition in terms of the relative amounts of $\mathrm{CO}$ and $\mathrm{CH}_{3} \mathrm{OH}$.

So far, $\left(\mathrm{CH}_{2} \mathrm{OH}\right)_{2}$ has been detected toward high-mass sources such as the Galactic center source Sgr B2(N) by Hollis et al. (2002), marginally toward W51 e1/e2 by Kalenskii \& Johansson (2010), and recently also toward the Orion Kleinmann-Low (KL) nebula by Brouillet et al. (2015). $\left(\mathrm{CH}_{2} \mathrm{OH}\right)_{2}$ has also been observed toward the low-mass Class 0 protostars IRAS 16293-2422 (Jørgensen et al. 2012, and in prep.) and NGC 1333 IRAS 2A (Maury et al. 2014; Coutens et al. 2015) as well as toward the intermediate-mass protostar NGC 7129 FIRS2 (Fuente et al. 2014). $\mathrm{CH}_{2} \mathrm{OHCHO}$ has been detected toward Sgr B2(N) (Hollis et al. 2000, 2001, 2004; Halfen et al. 2006; Requena-Torres et al. 2008), the high-mass hot molecular core G31.41+0.31 (Beltrán et al. 2009), in IRAS 16293-2422 by Jørgensen et al. (2012) and recently also in NGC 7129 FIRS2 (Fuente et al. 2014), NGC 1333 IRAS 2A (Coutens et al. 2015; Taquet et al. 2015) and NGC 1333 IRAS $4 \mathrm{~A}$ (Taquet et al. 2015). $\mathrm{HCOOCH}_{3}$ is the most abundant isomer of $\mathrm{CH}_{2} \mathrm{OHCHO}$, and it has previously been observed in numerous hot cores and corinos (e.g., Blake et al. 1987; Bisschop et al. 2007; Demyk et al. 2008; Favre et al. 2014, 2011). There are some notable differences in terms of the abundance ratios. For example, Coutens et al. (2015) find a $\left(\mathrm{CH}_{2} \mathrm{OH}\right)_{2} / \mathrm{CH}_{2} \mathrm{OHCHO}$ ratio of $\sim 5$ in NGC 1333 IRAS 2A, while Jørgensen et al. (2012 and in prep.) find a lower value of $\sim 1$ in IRAS 16293-2422. These changes hint that it might be useful to explore these ratios in different sources sampling similar physical conditions.

This paper presents IRAM $30 \mathrm{~m}$ observations of $\left(\mathrm{CH}_{2} \mathrm{OH}\right)_{2}$ and $\mathrm{CH}_{2} \mathrm{OHCHO}$ toward the high-mass protostars W51/e2 (distance $=5.4 \mathrm{kpc}$, Sato et al. 2010) and G34.3+0.2 (distance $=$ $3.8 \mathrm{kpc}$, Kurtz et al. 2000). The aim of this study is to determine the relative abundance of $\left(\mathrm{CH}_{2} \mathrm{OH}\right)_{2}$ and $\mathrm{CH}_{2} \mathrm{OHCHO}$ to $\mathrm{HCOOCH}_{3}$ and compare to other sources from the literature. Overall our aim is to investigate the use of abundance ratios of species that are believed to be chemically related to explore the origin of complex molecules in the dense interstellar medium. In Sect. 2, the IRAM 30 m observations are presented. Data modeling, results and analysis are presented in Sect. 3 and discussed in Sect. 4.

\section{Observations}

The observations were performed with the IRAM $30 \mathrm{~m}$ telescope at Pico Veleta, Spain on December 13 and 14, 2012 for W51/e2 and G34.3+0.2, respectively. The coordinates of the phase tracking center used for the two sources were $\alpha_{\mathrm{J} 2000}=19^{\mathrm{h}} 23^{\mathrm{m}} 43^{\mathrm{s}} .9$, $\delta_{\mathrm{J} 2000}=14^{\circ} 30^{\prime} 34^{\prime \prime} .8$ for $\mathrm{W} 51 / \mathrm{e} 2$ and $\alpha_{\mathrm{J} 2000}=18^{\mathrm{h}} 53^{\mathrm{m}} 18^{\mathrm{s}} .6$, $\delta_{\mathrm{J} 2000}=01^{\circ} 14^{\prime} 58^{\prime \prime} .0$ for $\mathrm{G} 34.3+0.2$. The observations were performed in position-switching mode using $\left[-600^{\prime \prime}, 0^{\prime \prime}\right]$ as reference for the OFF positions. The spectral setup was chosen to target $\left(\mathrm{CH}_{2} \mathrm{OH}\right)_{2}$ and $\mathrm{CH}_{2} \mathrm{OHCHO}$ in the observations. The EMIR receiver was used in dual-band polarisation (E090/E230) in connection with i) the $200 \mathrm{kHz}$ Fourier transform spectrometer (FTS) backend in the frequency ranges $99.70-106.3 \mathrm{GHz}$ and 238.2-246.0 GHz for the E090 and E230 bands, respectively; ii) the WILMA backend in the frequency ranges 99.88103.6 GHz and 238.4-242.1 GHz for the E090 and E230 bands, respectively. Data was reduced with the Continuum and Line Analysis Single-dish Software ${ }^{1}$ (CLASS). The resulting FTS spectra were smoothed to a spectral resolution of $1.15 \mathrm{~km} \mathrm{~s}^{-1}$

http://www.iram.fr/IRAMFR/GILDAS for the E090 band and $1.22 \mathrm{~km} \mathrm{~s}^{-1}$ for the E230 band, while the WILMA spectra were smoothed to $5.88 \mathrm{~km} \mathrm{~s}^{-1}$ and $2.49 \mathrm{~km} \mathrm{~s}^{-1}$ for the E090 and E230 bands, respectively. Spectra resulting from the FTS backend presented a standing wave pattern, and the WILMA observations were therefore used as a sanity check for the FTS data and for confirmation of the detections made in the FTS observations for the lines where the frequency of the two sets of observations match. The standing wave present in the FTS observations was removed using a fast Fourier transform in the data reduction.

Throughout this paper, the intensity is given as the main beam brightness temperature $\left(T_{\mathrm{mb}}\right)$, which is defined as

$T_{\mathrm{mb}}=T_{\mathrm{a}} \times \frac{F_{\mathrm{eff}}}{B_{\mathrm{eff}}}$

where $T_{\mathrm{a}}$ is the antenna temperature, $F_{\text {eff }}$ the forward efficiency and $B_{\text {eff }}$ the beam efficiency. The values used were $F_{\text {eff }}=0.94$ and 0.92 and $B_{\text {eff }}=0.78$ and 0.58 for $1 \mathrm{~mm}$ and $3 \mathrm{~mm}$ respectively. The half-power beam sizes are $\sim 10^{\prime \prime}$ and $\sim 24^{\prime \prime}$ for the observations at $1 \mathrm{~mm}$ and $3 \mathrm{~mm}$, respectively.

\section{Analysis and results}

Spectra from both sources show a rich forest of lines characteristic of high-mass sources. A total of 21 and 19 lines have peak temperatures above $5 \mathrm{~K}$ for $\mathrm{W} 51 / \mathrm{e} 2$ and $\mathrm{G} 34.3+0.2$, respectively. The strongest lines in both spectra are the CS 5-4 transition at $244935 \mathrm{MHz}$. It is important to know that there is still a remnant oscillation in the baseline even after the removal of the standing wave in the spectra. This increases the rms noise of the spectra, which complicates the analysis of faint lines. Therefore, in addition to the global baseline subtraction, an additional local zero-, or first-order baseline subtraction was therefore performed before making a Gaussian fit of the $\left(\mathrm{CH}_{2} \mathrm{OH}\right)_{2}$ lines. This additional baseline subtraction is applied in a range of $\pm 100 \mathrm{~km} \mathrm{~s}^{-1}$ for each line. As for the data reduction, CLASS was used for the additional baseline subtraction, as well as for Gaussian profile fits to the detected lines. The resulting rms of the local baseline is $\sim 60 \mathrm{mK}$ for the $1 \mathrm{~mm}$ observations and $\sim 7 \mathrm{mK}$ for the $3 \mathrm{~mm}$ observations.

To ensure proper line identification, we checked the line observations against entries in the Splatalogue database for astronomical spectroscopy ${ }^{2}$. In addition, we made a reference model where we produced synthetic spectra for the line emission of common species $\left(\mathrm{CH}_{3} \mathrm{OCH}_{3}, \mathrm{HCOOH}, \mathrm{CH}_{3} \mathrm{CHO}, \mathrm{CH}_{3} \mathrm{OH}\right.$, $\mathrm{C}_{2} \mathrm{H}_{5} \mathrm{OH}$ and $\mathrm{CH}_{3} \mathrm{CN}$ ) in order to visually exclude lines that are blended with any of these molecules. Table 1 lists spectroscopic parameters for the $\left(\mathrm{CH}_{2} \mathrm{OH}\right)_{2}$ transitions that can be excited in the observed frequency range. Transitions with $\log \left(A_{\mathrm{ul}}\right)<-5$ for the $3 \mathrm{~mm}$ observations and $\log \left(A_{\mathrm{ul}}\right)<-4$ and $E_{\mathrm{up}}>300 \mathrm{~K}$ for the $1 \mathrm{~mm}$ observations have been excluded from the table, because these transitions are predicted from the synthetic spectra to have peak intensities $\lesssim 0.02 \mathrm{~K}$, i.e., are not detectable.

The spectroscopic data for $\left(\mathrm{CH}_{2} \mathrm{OH}\right)_{2}$ come from Christen \& Müller (2003) and Christen et al. (1995) and are available from the CDMS database ${ }^{3}$ (Müller et al. 2001, 2005), while the spectroscopic data for $\mathrm{HCOOCH}_{3}$ and $\mathrm{CH}_{2} \mathrm{OHCHO}$ are from Ilyushin et al. (2009) and Carroll et al. (2010) respectively, available from the JPL database ${ }^{4}$ (Pickett et al. 1998). For the analysis, the $\left(\mathrm{CH}_{2} \mathrm{OH}\right)_{2}$ lines that are reasonably well separated and

\footnotetext{
2 http://www.splatalogue.net

3 http://www.astro.uni-koeln.de/cdms

4 http://spec.jpl.nasa.gov/home.html
} 
J. M. Lykke et al.: Tentative detection of ethylene glycol toward W51/e2 and G34.3+0.2

Table 1. Transitions of $\left(\mathrm{CH}_{2} \mathrm{OH}\right)_{2}$ in the observed frequency range.

\begin{tabular}{|c|c|c|c|c|}
\hline Transition & $\begin{array}{c}\text { Frequency } \\
{[\mathrm{MHz}]}\end{array}$ & $\begin{array}{l}E_{\text {up }} \\
{[\mathrm{K}]}\end{array}$ & $\begin{array}{c}\log _{10}\left(A_{\mathrm{ul}}\right) \\
{\left[\mathrm{s}^{-1}\right]}\end{array}$ & Rotational diagram \\
\hline \multicolumn{5}{|c|}{$3 \mathrm{~mm}$ observations } \\
\hline $9_{1,8} v=1-8_{1,7} v=0$ & 100333.6424 & 23.6 & -4.6773 & $\mathrm{~W} 51 / \mathrm{e} 2$ \\
\hline $9_{3,6} v=1-83,5 v=0$ & 100490.6121 & 27.0 & -4.6800 & \\
\hline $11_{1,10} v=1-10_{2,9} v=1$ & 102064.0770 & 33.9 & -4.6692 & \\
\hline $10_{1,10} v=1-9_{1,9} v=0$ & 102291.5860 & 26.2 & -4.5798 & \\
\hline $9_{2,7} v=1-8_{2,6} v=0$ & 102539.4267 & 25.0 & -4.6355 & \\
\hline $10_{0,10} v=1-9_{0,9} v=0$ & 102689.8384 & 26.1 & -4.4419 & \\
\hline $11_{9,2} v=0-10_{9,1} v=1$ & 105574.9490 & 72.2 & -4.9342 & \\
\hline $11_{8,4 / 3} v=0-10_{8,3 / 2} v=1$ & 105644.1940 & 63.9 & -4.5179 & \\
\hline $11_{1,10} v=0-10_{1,9} v=1$ & 105701.0020 & 33.6 & -4.3644 & \\
\hline $11_{7,5 / 4} v=0-10_{7,4 / 3} v=1$ & 105735.3520 & 56.5 & -4.4051 & \\
\hline $11_{3,9} v=0-10_{3,8} v=1$ & 105834.6960 & 36.9 & -4.5676 & \\
\hline $11_{6,6 / 5} v=0-10_{6,5 / 4} v=1$ & 105866.9546 & 50.1 & -4.3228 & \\
\hline $11_{5,7} v=0-10_{5,6} v=1$ & 106072.0524 & 44.7 & -4.6197 & \\
\hline $11_{5,6} v=0-10_{5,5} v=1$ & 106088.9178 & 44.8 & -4.5104 & \\
\hline \multicolumn{5}{|c|}{$1 \mathrm{~mm}$ observations } \\
\hline $24_{17,8 / 7} v=0-23_{17,7 / 6} v=1$ & 238828.3252 & 289.3 & -3.4806 & \\
\hline $24_{16,9 / 8} v=0-23_{16,8 / 7} v=1$ & 238904.3833 & 273.1 & -3.4330 & \\
\hline $24_{15,10 / 9} v=0-23_{15,9 / 8} v=1$ & 238993.6343 & 257.9 & -3.3925 & \\
\hline $30_{12,19 / 18} v=1-30_{11,19 / 20} v=0$ & 238994.0910 & 299.7 & -4.8643 & \\
\hline $22_{5,17} v=1-21_{5,16} v=0$ & 238994.7545 & 138.6 & -3.5149 & \\
\hline $24_{13,12 / 11} v=0-23_{13,11 / 10} v=1$ & 239231.3329 & 230.4 & -3.3269 & \\
\hline $24_{12,13 / 12} v=0-23_{12,12 / 11} v=1$ & 239395.0677 & 218.2 & -3.3002 & \\
\hline $24_{11,14 / 13} v=0-23_{11,13 / 12} v=1$ & 239605.3330 & 206.9 & -3.2765 & \\
\hline $25_{3,23} v=0-24_{3,22} v=1$ & 239792.7984 & 161.6 & -3.4697 & \\
\hline $24_{10,15 / 14} v=0-23_{10,14 / 13} v=1$ & 239883.5631 & 196.7 & -3.2555 & W51/e2 \\
\hline $25_{2,23} v=0-24_{2,22} v=1$ & 239957.1582 & 161.6 & -3.4917 & \\
\hline $23_{4,20} v=1-22_{4,19} v=0$ & 239980.0390 & 144.1 & -3.4495 & \\
\hline $24_{3,21} v=0-23_{3,20} v=1$ & 240147.9627 & 155.2 & -3.4704 & \\
\hline $24_{9,16 / 15} v=0-23_{9,15 / 14} v=1$ & 240265.7687 & 187.4 & -3.2365 & \\
\hline $22_{4.19} v=0-21_{3.18} v=0$ & 240608.1463 & 132.6 & -3.9839 & \\
\hline $25_{1 / 0,25} v=1-24_{1 / 0,24} v=0$ & 240778.3210 & 148.0 & -3.1643 & \\
\hline $24_{8,17} v=0-23_{8,16} v=1$ & 240807.8795 & 179.2 & -3.5201 & $\mathrm{~W} 51 / \mathrm{e} 2$ and $\mathrm{G} 34.3+0.2$ \\
\hline $24_{8,16} v=0-23_{8,15} v=1$ & 240828.8863 & 179.2 & -3.5199 & \\
\hline $22_{4,18} v=1-21_{4,17} v=0$ & 240875.3680 & 135.5 & -3.4905 & \\
\hline $59_{10,50} v=1-59_{9,51} v=1$ & 240888.3533 & 925.5 & -4.4992 & \\
\hline $24_{5,20} v=023_{5,19} v=1$ & 241291.2695 & 160.7 & -3.5046 & \\
\hline $24_{7,18} v=0-23_{7,17} v=1$ & 241545.2626 & 172.1 & -3.5045 & \\
\hline $24_{7,17} v=0-23_{7,16} v=1$ & 241817.6908 & 172.1 & -3.5026 & \\
\hline $24_{6,19} v=0-23_{6,18} v=1$ & 241860.7330 & 166.0 & -3.5459 & \\
\hline $23_{15,9 / 8} v=1-22_{15,8 / 7} v=0$ & 242244.6928 & 246.4 & -3.4004 & \\
\hline $23_{14,10 / 9} v=1-2214,9 / 8 v=0$ & 242246.3392 & 232.2 & -3.3608 & \\
\hline $23_{16,8 / 7} v=1-22_{16,7 / 6} v=0$ & 242267.1576 & 261.6 & -3.4470 & \\
\hline $23_{13,11 / 10} v=1-22_{13,10 / 9} v=0$ & 242277.7167 & 218.9 & -3.3268 & \\
\hline $23_{17,7 / 6} v=1-22_{17,6 / 5} v=0$ & 242309.7823 & 277.8 & -3.5027 & \\
\hline $23_{12,12 / 11} v=1-22_{12,11 / 10} v=0$ & 242347.0348 & 206.7 & -3.2973 & \\
\hline $23_{18,6 / 5} v=1-22_{18,5 / 4} v=0$ & 242369.7298 & 295.0 & -3.5709 & \\
\hline $26_{2 / 1,25} v=0-25_{2 / 1,24} v=1$ & 242389.2838 & 166.9 & -3.1601 & \\
\hline $23_{11,13 / 12} v=1-22_{11,12 / 11} v=0$ & 242466.6909 & 195.4 & -3.2714 & \\
\hline $23_{10,14 / 13} v=1-22_{10,13 / 12} v=0$ & 242656.2283 & 185.2 & -3.2486 & $\mathrm{~W} 51 / \mathrm{e} 2$ and $\mathrm{G} 34.3+0.2$ \\
\hline $23_{3,20} v=1-22319 v=0$ & 242897.4293 & 143.6 & -3.7464 & \\
\hline $23_{9,15 / 14} v=1-22_{9,14 / 13} v=0$ & 242948.2909 & 175.9 & -3.2282 & W51/e2 \\
\hline $24_{6,18} v=0-23_{6,17} v=1$ & 243259.7398 & 166.3 & -3.8001 & \\
\hline $23_{8,16} v=1-22_{8,15} v=0$ & 243396.0258 & 167.7 & -3.5106 & \\
\hline $23_{8,15} v=1-22,14 v=0$ & 243408.4357 & 167.7 & -3.5105 & \\
\hline $23_{5,19} v=1-22_{5_{1} 8} v=0$ & 243636.5668 & 149.1 & -3.4704 & \\
\hline $237,17 v=1-227.16 v=0$ & 244054.2878 & 160.5 & -3.4934 & \\
\hline $23_{7,16} v=1-227,15 v=0$ & 244233.4545 & 160.5 & -3.4927 & \\
\hline $24_{3,22} v=1-23_{3,21} v=0$ & 244399.6722 & 150.1 & -3.4754 & \\
\hline $24_{2,22} v=1-23_{2,21} v=0$ & 244685.1477 & 150.1 & -3.4399 & \\
\hline $23_{6,18} v=1-22_{6,17} v=0$ & 244879.9193 & 154.4 & -3.5188 & \\
\hline $27_{1 / 0,27} v=0-26_{1 / 0,26} v=1$ & 245022.7624 & 171.4 & -3.1407 & \\
\hline $24_{6,19} v=1-23_{6,17} v=1$ & 245410.9218 & 166.3 & -3.7580 & \\
\hline
\end{tabular}

Notes. Catalog values for the $\left(\mathrm{CH}_{2} \mathrm{OH}\right)_{2}$ transitions that can be excited in the observed frequency range for W51/e2 and G34.3+0.2. Some faint transitions have been excluded from this table, please Sect. 3. The source names are listed for the lines that are used in the rotational diagram analysis. 

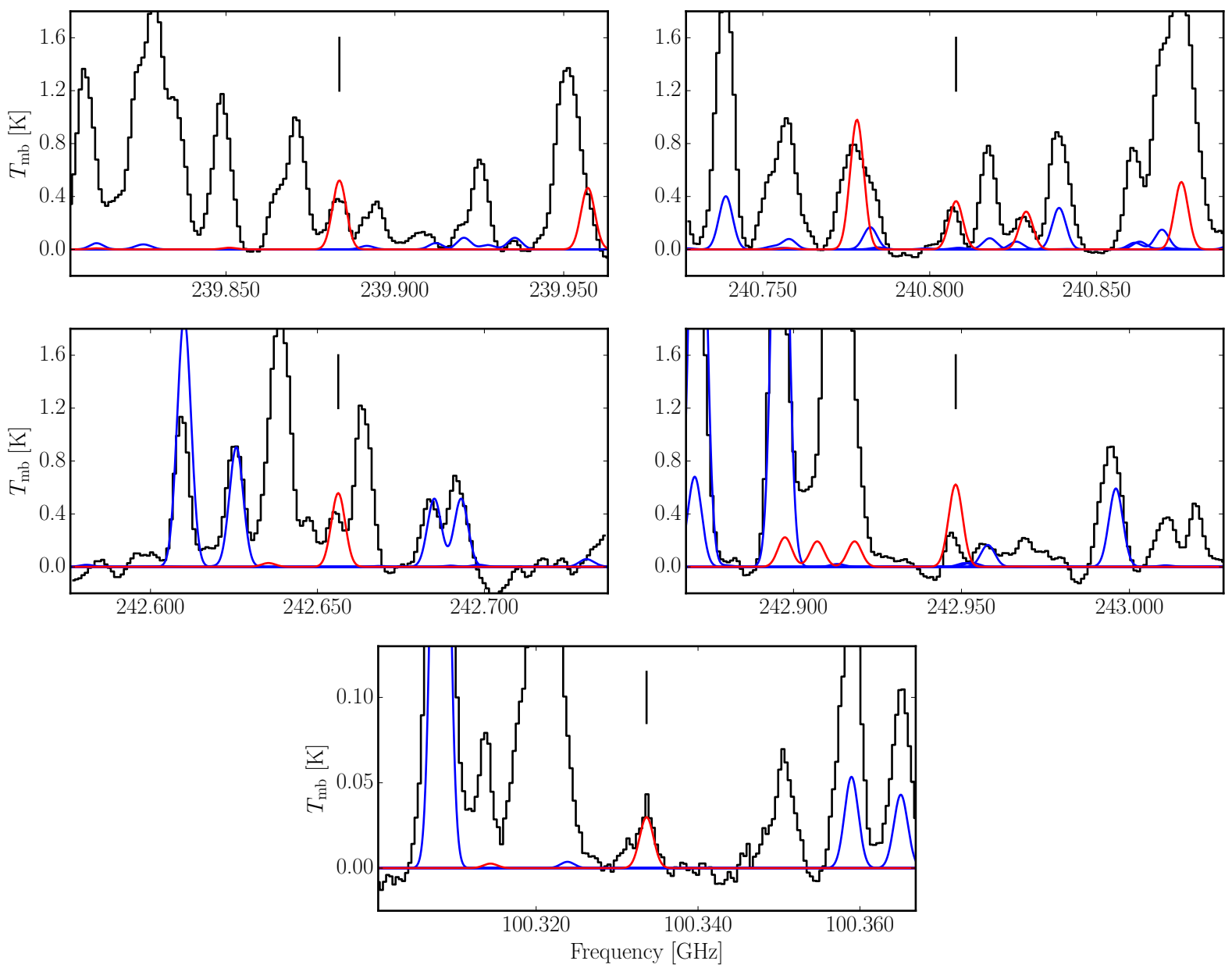

Fig. 1. Observed (black) and synthetic (red) spectra of the five transitions of $\left(\mathrm{CH}_{2} \mathrm{OH}\right)_{2}$ in W51/e2 that are used for the analysis. Also shown are the synthetic spectra of all other species investigated in this study (blue) to demonstrate that the $\left(\mathrm{CH}_{2} \mathrm{OH}\right)_{2}$ lines in question are not blended. The transitions are located at 239 883.56, $240807.88,242656.23,242948.29$ and $100333.64 \mathrm{MHz}$ - denoted by black vertical lines in the plot. The displayed frequency region in each plot corresponds to $\sim 200 \mathrm{~km} \mathrm{~s}^{-1}$.


Fig. 2. Same as for Fig. 1 but for G34.3+0.2. The transitions are located at 240807.88 and $242656.23 \mathrm{MHz}$ - indicated by black vertical lines in the plot.

have a peak temperature above $3 \sigma$ were selected. For W51/e2 we included the lines at $\sim 100333$ and $\sim 242656 \mathrm{MHz}$, although they are partially blended, because it is possible to distinguish the $\left(\mathrm{CH}_{2} \mathrm{OH}\right)_{2}$ peak from the other peaks and perform a multiple Gaussian fit that includes all relevant peaks.

Figures 1 and 2 show a zoom-in of the area of $\sim 200 \mathrm{~km} \mathrm{~s}^{-1}$, which corresponds to $\sim 160 \mathrm{MHz}$ in the $1 \mathrm{~mm}$ observations and $\sim 70 \mathrm{MHz}$ in the $3 \mathrm{~mm}$ observations, around each detected line in both sources after the local baseline subtraction. Superimposed onto the observed spectra are the synthetic spectra of $\left(\mathrm{CH}_{2} \mathrm{OH}\right)_{2}$ as well as the other species investigated here, as to demonstrate that the chosen $\left(\mathrm{CH}_{2} \mathrm{OH}\right)_{2}$ lines are not blended. The fit to the entire observed spectra for both sources are shown in Figs. B.1-B.8 in the appendix. Table A.1 in the appendix lists the estimated column densities of the molecules in the reference model. Table 2 lists spectroscopic parameters and the observed quantities from the fits of the $\left(\mathrm{CH}_{2} \mathrm{OH}\right)_{2}$ lines: the integrated line intensity $\left(\int T_{\mathrm{mb}} \Delta v\right)$, position $\left(V_{\mathrm{LSR}}\right)$, line width $(\Delta v)$ and peak temperature (Peak $T_{\mathrm{mb}}$ ).

A total of 35 and 52 well separated lines have been detected above the $3 \sigma$ level in the $1 \mathrm{~mm}$ and $3 \mathrm{~mm}$ data for $\mathrm{HCOOCH}_{3}$ in W51/e2 and G34.3+0.2, respectively. For $\left(\mathrm{CH}_{2} \mathrm{OH}\right)_{2}$, four and 
Table 2. Transitions of $\left(\mathrm{CH}_{2} \mathrm{OH}\right)_{2}$ observed toward W51/e2 and G34.3+0.2 with the IRAM 30-m telescope.

\begin{tabular}{lccccccc}
\hline \hline $\begin{array}{l}\text { Transition } \\
J_{K_{a}, K_{c}}^{\prime} v^{\prime}-J_{K_{a}, K_{c}}^{\prime \prime} v^{\prime \prime}\end{array}$ & $\begin{array}{c}\text { Freq. } \\
{[\mathrm{MHz}]}\end{array}$ & $\begin{array}{c}E_{\mathrm{up}} \\
{[\mathrm{K}]}\end{array}$ & $\begin{array}{c}\log _{10} \mathrm{~A}_{\mathrm{ul}} \\
{\left[\mathrm{s}^{-1}\right]}\end{array}$ & $\begin{array}{c}\int T_{\mathrm{mb}} \Delta v \\
{\left[\mathrm{~K} \mathrm{~km} \mathrm{~s}^{-1}\right]}\end{array}$ & $\begin{array}{c}V_{\mathrm{LSR}} \\
{\left[\mathrm{km} \mathrm{s}^{-1}\right]}\end{array}$ & $\begin{array}{c}\Delta v \\
{\left[\mathrm{~km} \mathrm{~s}^{-1}\right]}\end{array}$ & $\begin{array}{c}\text { Peak } T_{\mathrm{mb}} \\
{[\mathrm{K}]}\end{array}$ \\
\hline $9_{1,8} v=1-8_{1,7} v=0$ & 100333.64 & 24 & -4.6773 & 0.2 & 55.1 & 5.5 & 0.03 \\
$24_{10,15 / 14} v=0-23_{10,14 / 13} v=1$ & 239883.56 & 197 & -3.2555 & 2.7 & 55.6 & 6.8 & 0.38 \\
$24_{8,17} v=0-23_{8,16} v=1$ & 240807.88 & 179 & -3.5201 & 2.0 & 56.7 & 5.9 & 0.32 \\
$23_{10,14 / 13} v=1-22_{10,13 / 12} v=0$ & 242656.23 & 185 & -3.5496 & 4.0 & 56.9 & 7.4 & 0.50 \\
$23_{9,15 / 14} v=1-22_{9,14 / 13} v=0$ & 242948.29 & 176 & -3.5292 & 1.4 & 56.5 & 5.0 & 0.27 \\
\hline & \multicolumn{7}{c}{$\mathrm{G} 34.3+0.2$} \\
\hline $24_{8,17} v=0-23_{8,16} v=1$ & 240807.88 & 179 & -3.5201 & 1.0 & 57.7 & 4.1 & 0.23 \\
$23_{10,14 / 13} v=1-22_{10,13 / 12} v=0$ & 242656.23 & 185 & -3.5496 & 1.0 & 58.4 & 5.0 & 0.19 \\
\hline
\end{tabular}

Notes. The table lists spectroscopic parameters and observed quantities from Gaussian fits to the detected $\left(\mathrm{CH}_{2} \mathrm{OH}\right)_{2}$ lines: integrated line intensity ( $\int T_{\mathrm{mb}} \Delta v$ ), line position $\left(V_{\mathrm{LSR}}\right)$, line width $(\Delta v)$ and peak temperature (Peak $T_{\mathrm{mb}}$ ). The error of $\int T_{\mathrm{mb}} \Delta v$ is estimated to $\sim 30 \%$ as determined by the observational uncertainty, while the errors on $V_{\mathrm{LSR}}$ and $\Delta v$ are $\sim 1.0 \mathrm{~s}^{-1}$ and $\sim 2.0 \mathrm{~km} \mathrm{~s}^{-1}$, respectively. The line intensities have been added together for the hyper fine structure transitions (denoted by / in the quantum numbers).

two lines toward W51/e2 and G34.3+0.2 respectively, are detected in the $1 \mathrm{~mm}$ observations; while only one line is detected at $3 \mathrm{~mm}$ toward W51/e2. Many other $\left(\mathrm{CH}_{2} \mathrm{OH}\right)_{2}$ lines, as well as some potential $\mathrm{CH}_{2} \mathrm{OHCHO}$ lines are present in both data sets, but they are either blended with other species or too faint to be properly detected above a $3 \sigma$ limit.

\subsection{Modeling}

Assuming LTE and optically thin emission, the rotational diagram method can be used to determine the column density, $N_{\text {tot }}$, and the rotational temperature, $T_{\text {rot }}$ (Goldsmith \& Langer 1999). The approach used in this work follows the formalism described by Goldsmith \& Langer (1999) with the following assumptions:

1. $\left(\mathrm{CH}_{2} \mathrm{OH}\right)_{2}, \mathrm{CH}_{2} \mathrm{OHCHO}$, and $\mathrm{HCOOCH}_{3}$ are emitting from the same region and thus have the same source size, $\theta_{\text {source. }}$

2. $\left(\mathrm{CH}_{2} \mathrm{OH}\right)_{2}, \mathrm{CH}_{2} \mathrm{OHCHO}$, and $\mathrm{HCOOCH}_{3}$ are in LTE, which implies that the excitation temperature, $T_{\mathrm{ex}}$, is equal to the kinematic temperature, $T_{\text {kin }}$, for all three species. Using the rotational diagram method, one obtains the rotational temperature, which in LTE is $T_{\text {kin }}=T_{\text {rot }}=T_{\text {ex }}$.

3. The observations at $1 \mathrm{~mm}$ and $3 \mathrm{~mm}$ trace the same gas.

According to our assumptions, the source size and $T_{\text {rot }}$ derived from the $\mathrm{HCOOCH}_{3}$ analysis can be used to derive the column density of $\left(\mathrm{CH}_{2} \mathrm{OH}\right)_{2}$ and set an upper limit on the column density of $\mathrm{CH}_{2} \mathrm{OHCHO}$. A possible caveat is that the large beam size of our observations compared to the source sizes does not guarantee that the measured lines arise from species present in the same gas. Specifically, we obtain similar mean values of $V_{\mathrm{LSR}}$ for $\left(\mathrm{CH}_{2} \mathrm{OH}\right)_{2}$ and $\mathrm{HCOOCH}_{3}$ in both sources $\left(56.4 \pm 0.5 \mathrm{~km} \mathrm{~s}^{-1}\right.$ and $56.0 \pm 0.8 \mathrm{~km} \mathrm{~s}^{-1}$ in W51/e2 along with $57.7 \pm 0.5 \mathrm{~km} \mathrm{~s}^{-1}$ and $58.4 \pm 1.2 \mathrm{~km} \mathrm{~s}^{-1}$ in $\mathrm{G} 34.3+0.2$ for $\left(\mathrm{CH}_{2} \mathrm{OH}\right)_{2}$ and $\mathrm{HCOOCH}_{3}$, respectively), so here the assumption appears reasonable.

The same formalism in Goldsmith \& Langer (1999) as was used to create a rotational diagram can also be used to generate a synthetic spectrum of the line emission of a specific molecule by using the source size, $\theta_{\text {source }}$, the rotational temperature, $T_{\text {rot }}$, the line width, $\Delta v$, and the column density, $N_{\text {tot }}$, as input parameters. It is possible to correct for the optical depth of the line emission in case it deviates from being completely optically thin (Goldsmith \& Langer 1999). A synthetic spectrum generated with input parameters derived from the rotational diagram therefore serves as a check for the self-consistency of the result. We use adopted source sizes from the literature and determine the rotational temperatures and column densities in the following analysis.

The observed width of the detected lines have been determined from the Gaussian fit. For $\mathrm{HCOOCH}_{3}$ in W51/e2, we obtain mean values of $\Delta v=6.4 \pm 0.8 \mathrm{~km} \mathrm{~s}^{-1}$ in the $1 \mathrm{~mm}$ data and $\Delta v=6.1 \pm 1.1 \mathrm{~km} \mathrm{~s}^{-1}$ in the $3 \mathrm{~mm}$ data. In the same source, the mean value of the line width of the $\left(\mathrm{CH}_{2} \mathrm{OH}\right)_{2}$ lines is $6.3 \pm 0.9 \mathrm{~km} \mathrm{~s}^{-1}$ for the $1 \mathrm{~mm}$ data, and the only detected value is $5.5 \mathrm{~km} \mathrm{~s}^{-1}$ in the $3 \mathrm{~mm}$ data. For G34.3+0.2, we find $\Delta v=6.5 \pm 1.5 \mathrm{~km} \mathrm{~s}^{-1}$ in the $1 \mathrm{~mm}$ data and $\Delta v=7.3 \pm 1.3 \mathrm{~km} \mathrm{~s}^{-1}$ in the $3 \mathrm{~mm}$ data for $\mathrm{HCOOCH}_{3}$ and $\Delta v=4.5 \pm 0.5 \mathrm{~km} \mathrm{~s}^{-1}$ for the $\left(\mathrm{CH}_{2} \mathrm{OH}\right)_{2}$ lines in the $1 \mathrm{~mm}$ data. In the analysis below, a fixed line width of $6.0 \mathrm{~km} \mathrm{~s}^{-1}$ was chosen as input parameter in synthetic spectra for all species.

\section{2. $\mathrm{HCOOCH}_{3}$}

In the rotational diagram analysis for W51/e2, a source size of 2.4" (Zhang et al. 1998) is applied and results in a rotation temperature of $T_{\text {rot }}=120 \mathrm{~K}$ and a column density of $1.1 \times 10^{18} \mathrm{~cm}^{-2}$. We estimate a $40 \mathrm{~K}$ uncertainty on the rotational temperature, which contribute to a $\sim 20 \%$ error on the column density. This, combined with an observational uncertainty of $\sim 30 \%$ returns an estimated overall error of $30 \%-40 \%$ for the column density. For G34.3+0.2 a source size of 7.6" (Remijan et al. 2003) is applied and results in $N_{\text {tot }}=5.8 \times 10^{16} \mathrm{~cm}^{-2}$, and $T_{\text {rot }}=140 \mathrm{~K}$ for $\mathrm{HCOOCH}_{3}$. As in the case for $\mathrm{W} 51 / \mathrm{e} 2$, the estimated uncertainty of the column density is $30 \%-40 \%$ and $40 \mathrm{~K}$ for the temperature. Results from both sources are given in Table 3, and we have checked the validity of these results by generating synthetic spectra and comparing these to the observed spectra.

\section{3. $\left(\mathrm{CH}_{2} \mathrm{OH}\right)_{2}$}

Numerous $\left(\mathrm{CH}_{2} \mathrm{OH}\right)_{2}$ lines are blended with other species or have line intensities below $3 \sigma$. A total of two and five reasonable well separated lines above the $3 \sigma$ limit toward G34.3+0.2 and W51/e2, respectively, were chosen for this analysis (see Tables 2 and 1 for the spectroscopic data and Figs. 1 and 2 for the zoom-in of the spectra around the lines). With only two to 
Table 3. Input parameters for synthetic spectra.

\begin{tabular}{lcc}
\hline \hline Parameter & $\mathrm{G} 34.3+0.2$ & W51/e2 \\
\hline$\theta_{\text {source }}\left[{ }^{\prime \prime}\right]$ & 7.6 & 2.4 \\
$T_{\text {rot }}[\mathrm{K}]$ & 140 & 120 \\
$\Delta v\left[\mathrm{~km} \mathrm{~s}^{-1}\right]$ & 6.0 & 6.0 \\
$\mathrm{HCOOCH}_{3} N_{\text {tot }}\left[\mathrm{cm}^{-2}\right]$ & $5.8 \times 10^{16}$ & $1.1 \times 10^{18}$ \\
$\left(\mathrm{CH}_{2} \mathrm{OH}\right)_{2} N_{\text {tot }}\left[\mathrm{cm}^{-2}\right]$ & $1.9 \times 10^{15}$ & $3.1 \times 10^{16}$ \\
$\mathrm{CH}_{2} \mathrm{OHCHO} N_{\text {tot }}\left[\mathrm{cm}^{-2}\right]$ & $\leq 3 \times 10^{14}$ & $\leq 2 \times 10^{15}$ \\
\hline
\end{tabular}

Notes. The source sizes, rotational temperatures, line widths and column densities which are used as input parameters when creating synthetic spectra. As described in the text, the estimated uncertainties are $\pm 40 \mathrm{~K}$ for $T_{\text {rot }}$ and $\pm 30 \%-40 \%$ for the column density.

five unblended lines, the assignment of $\left(\mathrm{CH}_{2} \mathrm{OH}\right)_{2}$ cannot be considered as a firm detection. However, even if our tentative detection of $\left(\mathrm{CH}_{2} \mathrm{OH}\right)_{2}$ is not confirmed, this measurement represents a useful upper limit for the column density of $\left(\mathrm{CH}_{2} \mathrm{OH}\right)_{2}$, which still can provide important information when compared to the $\mathrm{HCOOCH}_{3}$ detection.

When only a few data points are available, a statistically reliable result of the rotational temperature cannot be obtained from the traditional use of the rotational diagram method. Thus, we assume that $\left(\mathrm{CH}_{2} \mathrm{OH}\right)_{2}$ and $\mathrm{HCOOCH}_{3}$ emit at the same $T_{\mathrm{ex}}$, which in LTE is equal to $T_{\text {rot }}$. The uncertainty of the column density is, as for $\mathrm{HCOOCH}_{3}$, estimated to $30 \%-40 \%$.

Using $\theta_{\text {source }}=7.6^{\prime \prime}$ and $T_{\text {rot }}=140 \mathrm{~K}$, a column density of $1.9 \times 10^{15} \mathrm{~cm}^{-2}$ is derived for $\left(\mathrm{CH}_{2} \mathrm{OH}\right)_{2}$ toward $\mathrm{G} 34.3+0.2$. For W51/e2, a source size of $2.4^{\prime \prime}$ and $T_{\text {rot }}=120 \mathrm{~K}$ returns $N_{\text {tot }}=3.1 \times 10^{16} \mathrm{~cm}^{-2}$ for $\left(\mathrm{CH}_{2} \mathrm{OH}\right)_{2}$. These results, listed in Table 3, are used as input parameters for synthetic spectra in order to perform a sanity check. We checked each line in the synthetic spectra against the observed spectra for each source, and they all seem to provide a reasonable match, at least within the estimated uncertainty. Figures 1 and 2 shows the comparison of the synthetic spectra against the observed spectra. It is evident from Fig. 1 that the synthetic spectrum in the $1 \mathrm{~mm}$ data toward W51/e2 slightly overproduces the observed spectrum, while it reproduces the observed line in the $3 \mathrm{~mm}$ data. Since this line has a lower $E_{\text {up }}$ this could indicate that a lower excitation temperature would give a better fit. Indeed a fixed $T_{\text {rot }}=70 \mathrm{~K}$ in the rotational diagram returns the same column density, $N_{\text {tot }}=3.1 \times 10^{16} \mathrm{~cm}^{-2}$.

\section{4. $\mathrm{CH}_{2} \mathrm{OHCHO}$}

Several lines in the data might be assigned to $\mathrm{CH}_{2} \mathrm{OHCHO}$. However, they are either blended with the emission of other molecules or too faint (i.e., below the $3 \sigma$ limit), thus we cannot claim a detection. Nevertheless, we are able to obtain an upper limit for the column density. Following the assumptions stated in Sect. 3.1, synthetic spectra were generated using $\theta_{\text {source}}$, $T_{\text {rot }}$ and $\Delta v$ in Table 3 , allowing $N_{\text {tot }}$ to vary. More specifically, the upper limit of the column density is then determined by increasing the value until the synthetic spectra overproduces the observed spectra intensities at the locations of the $\mathrm{CH}_{2} \mathrm{OHCHO}$ lines in the observed spectra. The upper limit on the column density is $\leq 3 \times 10^{14} \mathrm{~cm}^{-2}$ toward G34.3+0.2 and $\leq 2 \times 10^{15} \mathrm{~cm}^{-2}$ toward W51/e2. The uncertainty of the column density is, as for $\mathrm{HCOOCH}_{3}$, estimated to $30 \%-40 \%$.

\subsection{Relative abundances}

Following the three assumptions listed in Sect. 3.1, it is possible to calculate the relative abundance of the species at the rotational temperature and source size found for each source. The following abundance ratios have been computed: $\mathrm{HCOOCH}_{3} /\left(\mathrm{CH}_{2} \mathrm{OH}\right)_{2}, \mathrm{HCOOCH}_{3} / \mathrm{CH}_{2} \mathrm{OHCHO}$ and $\left(\mathrm{CH}_{2} \mathrm{OH}\right)_{2} / \mathrm{CH}_{2} \mathrm{OHCHO}$. As $\mathrm{CH}_{2} \mathrm{OHCHO}$ is not detected, it is only possible to set an upper limit on the column density. The $\mathrm{HCOOCH}_{3} / \mathrm{CH}_{2} \mathrm{OHCHO}$ and $\left(\mathrm{CH}_{2} \mathrm{OH}\right)_{2} / \mathrm{CH}_{2} \mathrm{OHCHO}$ ratios are therefore lower limits. All three relative abundance ratios for W51/e 2 and G34.3+0.2 are listed in Table 4 along with previous measurements toward high-mass stars-forming regions, a hot core, an intermediate-mass protostar, low-mass protostars, molecular clouds toward the Galactic center and comets.

\section{Discussion}

$\left(\mathrm{CH}_{2} \mathrm{OH}\right)_{2}$ has previously been detected in several other sources (Sgr B2(N), NGC 7129 FIRS2, NGC 1333 IRAS 2A and Orion-KL), with additional marginal/tentative detections in W51 e1/e2 and IRAS 16293-2422 (Hollis et al. 2002; Fuente et al. 2014; Maury et al. 2014; Coutens et al. 2015; Kalenskii \& Johansson 2010; Jørgensen et al. 2012). In this paper we have identified $\left(\mathrm{CH}_{2} \mathrm{OH}\right)_{2}$ and $\mathrm{HCOOCH}_{3}$ in two highmass protostellar sources, W51/2 and G34.3+0.2, and in addition been able to give an upper limit for the column density of $\mathrm{CH}_{2} \mathrm{OHCHO}$ in the same sources. The results from this study are roughly similar to the estimates ratios seen in Orion KL (Favre et al. 2011; Brouillet et al. 2015) for the $\mathrm{HCOOCH}_{3} / \mathrm{CH}_{2} \mathrm{OHCHO}$ and $\mathrm{HCOOCH}_{3} /\left(\mathrm{CH}_{2} \mathrm{OH}\right)_{2}$ ratios while the upper limits for $\left(\mathrm{CH}_{2} \mathrm{OH}\right)_{2} / \mathrm{CH}_{2} \mathrm{OHCHO}$ are similar to the results for NGC 1333 IRAS 2A (Coutens et al. 2015), as well as the upper limits results for comets (Biver et al. 2014; Bockelée-Morvan et al. 2000; Crovisier et al. 2004a,b) (Table 4).

When investigating the conditions leading to differences in observed abundance ratios, it is important to take both the formation processes and the destruction processes of the molecules into consideration. Garrod et al. (2008) combined a gas-grain chemical network with a physical model to test whether the chemistry can reproduce the observed abundances of previously detected organic molecules in physical conditions characteristic of star-forming regions. The physical model used in Garrod et al. (2008) is based on Viti et al. (2004) and consist of an isothermal collapse followed by a warm-up phase with temperatures from $10 \mathrm{~K}$ to $200 \mathrm{~K}$, assuming absolute time scales for the warmup phases are $1 \times 10^{6}, 2 \times 10^{5}$, and $5 \times 10^{4}$ yr representing low-, intermediate-, and high-mass star formation respectively. However, Aikawa et al. (2008) argue that the relation should be reversed, because the warm-up time scale should be relative and should depend on the ratio of the size of the warm region to the infall speed instead of the overall speed of star formation. Either way, Garrod et al. (2008) and Aikawa et al. (2008) agree that the time scales, whether absolute or relative, at the different temperature ranges are important for the chemistry.

For all the sources in Table $4, \mathrm{HCOOCH}_{3}$ is more abundant than $\mathrm{CH}_{2} \mathrm{OHCHO}$ from a factor of $>550$ in W51/e 2 to a factor of $>2$ in comet Hale-Bopp. According to Garrod et al. (2008), $\mathrm{HCOOCH}_{3}$ and $\mathrm{CH}_{2} \mathrm{OHCHO}$ have similar formation pathways, which are based on the addition of $\mathrm{HCO}$ and $\mathrm{CH}_{3} \mathrm{O}$ or $\mathrm{CH}_{2} \mathrm{OH}$ at $30 \mathrm{~K}-40 \mathrm{~K}$. Garrod et al. (2008) find that the production rates of $\mathrm{CH}_{3} \mathrm{O}$ and $\mathrm{CH}_{2} \mathrm{OH}$ are the same, which leads to similar abundances for $\mathrm{HCOOCH}_{3}$ and $\mathrm{CH}_{2} \mathrm{OHCHO}$. Intuitively this makes sense because the two molecules are isomers, but it 
Table 4. Relative abundances of $\left(\mathrm{CH}_{2} \mathrm{OH}\right)_{2}, \mathrm{HCOOCH}_{3}$ and $\mathrm{CH}_{2} \mathrm{OHCHO}$ in different sources.

\begin{tabular}{|c|c|c|c|c|c|}
\hline Source & $\mathrm{HCOOCH}_{3} /\left(\mathrm{CH}_{2} \mathrm{OH}\right)_{2}$ & $\mathrm{HCOOCH}_{3} / \mathrm{CH}_{2} \mathrm{OHCHO}$ & $\left(\mathrm{CH}_{2} \mathrm{OH}\right)_{2} / \mathrm{CH}_{2} \mathrm{OHCHO}$ & $L_{\text {bol }}\left[L_{\odot}\right]$ & References \\
\hline W51/e2 (this study) & 35 & $>550$ & $>16$ & $4.7 \times 10^{6}$ & 1,2 \\
\hline Orion-KL ${ }^{a}$ & 35 & $>200-300$ & $>12$ & $10^{5}$ & 3,4 \\
\hline G34.3+0.2 (this study) & 31 & $>193$ & $>6$ & $2.8 \times 10^{5}$ & 1,5 \\
\hline Sgr B2(N) LMH ${ }^{b}$ & $\begin{array}{l}J 1 \\
-\end{array}$ & 52 & - & $\begin{array}{c}2.0 \times 10 \\
10^{7}\end{array}$ & 6,7 \\
\hline $\mathrm{G} 31.41+0.31^{c}$ & - & $<34$ & - & $1.8 \times 10^{5}$ & 8,5 \\
\hline NGC 7129 FIRS2 $^{d}$ & $\sim 15$ & $\sim 30$ & $\sim 2$ & 500 & 9 \\
\hline IRAS NGC $13332 \mathrm{~A}^{e}$ & 4 & 20 & 5 & 20 & 10,11 \\
\hline IRAS $16293-2422^{e}$ & $\sim 13$ & $\sim 13$ & $\sim 1$ & 27 & 12,13 \\
\hline IRAS NGC $13334 \mathrm{~A}^{e}$ & - & 10 & - & 7.7 & 14 \\
\hline $\mathrm{MC} \mathrm{G}+0.693^{f}$ & 4.3 & 5.2 & 1.2 & - & 15 \\
\hline MC G-0.11 $1^{f}$ & 2.8 & 4.3 & 1.6 & - & 15 \\
\hline MC G- $0.02^{f}$ & 2.5 & 3.3 & 1.3 & - & 15 \\
\hline Lemmon $^{g}$ & $<0.7$ & - & $>3$ & - & 16 \\
\hline LoveJoy $^{g}$ & $<0.6$ & - & $>5$ & - & 16 \\
\hline Hale-Bopp ${ }^{g}$ & 0.32 & $>2$ & $>6.25$ & - & 17 \\
\hline
\end{tabular}

Notes. The table show the results from similar studies of: ${ }^{(a)}$ the Orion Kleinmann-Low nebula, a high-mass star-forming region; ${ }^{(b)}$ the Large Molecule Heimat hot core source toward Sgr B2(N); ${ }^{(c)}$ high-mass star-forming region; ${ }^{(d)}$ intermediate-mass protostar; ${ }^{(e)}$ low-mass Class 0 protostars; $(f)$ molecular clouds in the Sgr A complex (MC G $-0.02-0.07$ ("the $50 \mathrm{~km} \mathrm{~s}^{-1}$ cloud") and MC G - $0.11-0.08$ ("the $20 \mathrm{~km} \mathrm{~s}^{-1}$ cloud")) and in the Sgr B2 complex (MC G + $0.693-0.03)$; and ${ }^{(g)}$ comets.

References. (1) this study; (2) Urquhart et al. (2014); (3) Favre et al. (2011), Brouillet et al. (2015); (4) Crockett et al. (2014); (5) van Dishoeck et al. (2011); (6) Hollis et al. (2001); (7) Goldsmith et al. (1990); (8) Beltrán et al. (2009); (9) Fuente et al. (2014); (10) Coutens et al. (2015); (11) Jørgensen et al. (2009); (12) Jørgensen et al. (2012, in prep.); (13) Schöier et al. (2002); (14) Taquet et al. (2015); (15) Requena-Torres et al. (2008); (16) Biver et al. (2014); (17) Bockelée-Morvan et al. (2000), Crovisier et al. (2004a,b).

contradicts observations because $\mathrm{HCOOCH}_{3}$ is observed to be much more abundant than $\mathrm{CH}_{2} \mathrm{OHCHO}$ in all the sources reported so far. As suggested by Garrod et al. (2008), this discrepancy could be due to the differences in the $\mathrm{CH}_{3} \mathrm{O} / \mathrm{CH}_{2} \mathrm{OH}$ branching ratio. According to Öberg et al. (2009), $\mathrm{HCOOCH}_{3}$ forms at a lower temperature than $\mathrm{CH}_{2} \mathrm{OHCHO}$, which can also have an impact on the resulting ratio of the two species. Another explanation for the high $\mathrm{HCOOCH} 3 / \mathrm{CH}_{2} \mathrm{OHCHO}$ ratio is the assumptions regarding thermal evaporation for these two species. Garrod et al. (2008) suggest that $\mathrm{CH}_{2} \mathrm{OHCHO}$ remains on the grains until is co-desorbs with water (at $\sim 110 \mathrm{~K}$ ) while $\mathrm{HCOOCH}_{3}$ evaporates at $70-80 \mathrm{~K}$. This leaves $\mathrm{CH}_{2} \mathrm{OHCHO}$ to be destroyed by $\mathrm{OH}$ radicals at higher temperatures on the grains prior to evaporation. As Öberg et al. (2009) conclude, the ratio of $\mathrm{HCOOCH}_{3} / \mathrm{CH}_{2} \mathrm{OHCHO}$ does not depend greatly on the initial ice composition, and so the observed variations will most likely be linked to the different temperature conditions of the different sources.

In Table 4 the sources are listed in order with a decreasing $\mathrm{HCOOCH} / \mathrm{CH}_{2} \mathrm{OHCHO}$ ratio, which in turn also roughly correspond to a descending order of luminosity, which is also listed in the table. The top plot in Fig. 3 shows a schematic bar plot of $\mathrm{HCOOCH}_{3} / \mathrm{CH}_{2} \mathrm{OHCHO}$ against $L_{\mathrm{bol}}$. On the $x$-axis the sources in Table 4 have been plotted in descending order from left to right, but not to scale. As illustrated by Fig. 3 (top) a rough correlation between $\mathrm{HCOOCH}_{3} / \mathrm{CH}_{2} \mathrm{OHCHO}$ and $L_{\text {bol }}$ exists: more luminous sources show a high $\mathrm{HCOOCH} 3 / \mathrm{CH}_{2} \mathrm{OHCHO}$ ratio, while lowluminosity sources show a low $\mathrm{HCOOCH}_{3} / \mathrm{CH}_{2} \mathrm{OHCHO}$ ratio with intermediate values in between. The apparent correlation between $\mathrm{HCOOCH} / \mathrm{CH}_{2} \mathrm{OHCHO}$ and source luminosity supports the hypothesis that the $\mathrm{HCOOCH} 3 / \mathrm{CH}_{2} \mathrm{OHCHO}$ ratio depends mainly on the temperature, which in turns depends on the luminosity of the source. Even if the chemistry and the temperature profile in all the sources were quite similar, the differences in time scales of the different temperature ranges (low, intermediate, to high temperature) are not. A higher $\mathrm{HCOOCH}_{3} / \mathrm{CH}_{2} \mathrm{OHCHO}$ ratio in more luminous sources could simply be a consequence of i) more luminous sources having experienced a longer time scale at temperatures that are either more favorable to the formation of $\mathrm{HCOOCH}_{3}$ and/or to the destruction of $\mathrm{CH}_{2} \mathrm{OHCHO}$; or ii) less luminous sources experience a shorter time scale at high temperature, which would conserve a greater fraction of $\mathrm{CH}_{2} \mathrm{OHCHO}$ than their more luminous counterparts. One should of course keep in mind that the sources discussed here have temperature profiles that covers a range of temperatures falling of with radius and that hot core regions are permeated by shocks that also produce a range of temperatures. For the Galactic center molecular clouds from the study by Requena-Torres et al. (2008), no luminosities are listed: these are warm, low-density clouds with no sign of star formation. However, judging by the $\mathrm{HCOOCH}_{3} / \mathrm{CH}_{2} \mathrm{OHCHO}$ and $\mathrm{HCOOCH}_{3} /\left(\mathrm{CH}_{2} \mathrm{OH}\right)_{2}$ ratios, they appear to be closer to the low-mass protostars than to the hot cores and high-mass star-forming regions.

In the bottom plot in Fig. 3, the $\mathrm{HCOOCH}_{3} /\left(\mathrm{CH}_{2} \mathrm{OH}\right)_{2}$ abundance ratio also shows a decrease with $L_{\mathrm{bol}}$ similar to that of $\mathrm{HCOOCH}_{3} / \mathrm{CH}_{2} \mathrm{OHCHO}$. If the same temperature time scale argument is applied to this correlation, one would expect an opposite trend, because $\left(\mathrm{CH}_{2} \mathrm{OH}\right)_{2}$ is formed a high temperatures (Garrod et al. 2008). A possible explanation for this seeming contradiction is that less luminous sources might experience high temperatures on time scales, that are just long enough for $\left(\mathrm{CH}_{2} \mathrm{OH}\right)_{2}$ to form, but not long enough for $\left(\mathrm{CH}_{2} \mathrm{OH}\right)_{2}$ to be destroyed again. Another possible explanation is that the initial ice composition affects the abundance ratio. While the $\mathrm{HCOOCH}_{3} / \mathrm{CH}_{2} \mathrm{OHCHO}$ ratio is independent of initial ice composition, then the formation of $\left(\mathrm{CH}_{2} \mathrm{OH}\right)_{2}$ is strongly correlated to the $\mathrm{CH}_{3} \mathrm{OH}: \mathrm{CO}$ composition of the ice (Öberg et al. 2009). Öberg et al. (2009) show that pure $\mathrm{CH}_{3} \mathrm{OH}$ ice enhances the $\left(\mathrm{CH}_{2} \mathrm{OH}\right)_{2}$ abundance as compared to ice mixes containing $\mathrm{CO}$. This is in agreement with the predictions by Garrod et al. (2008) 

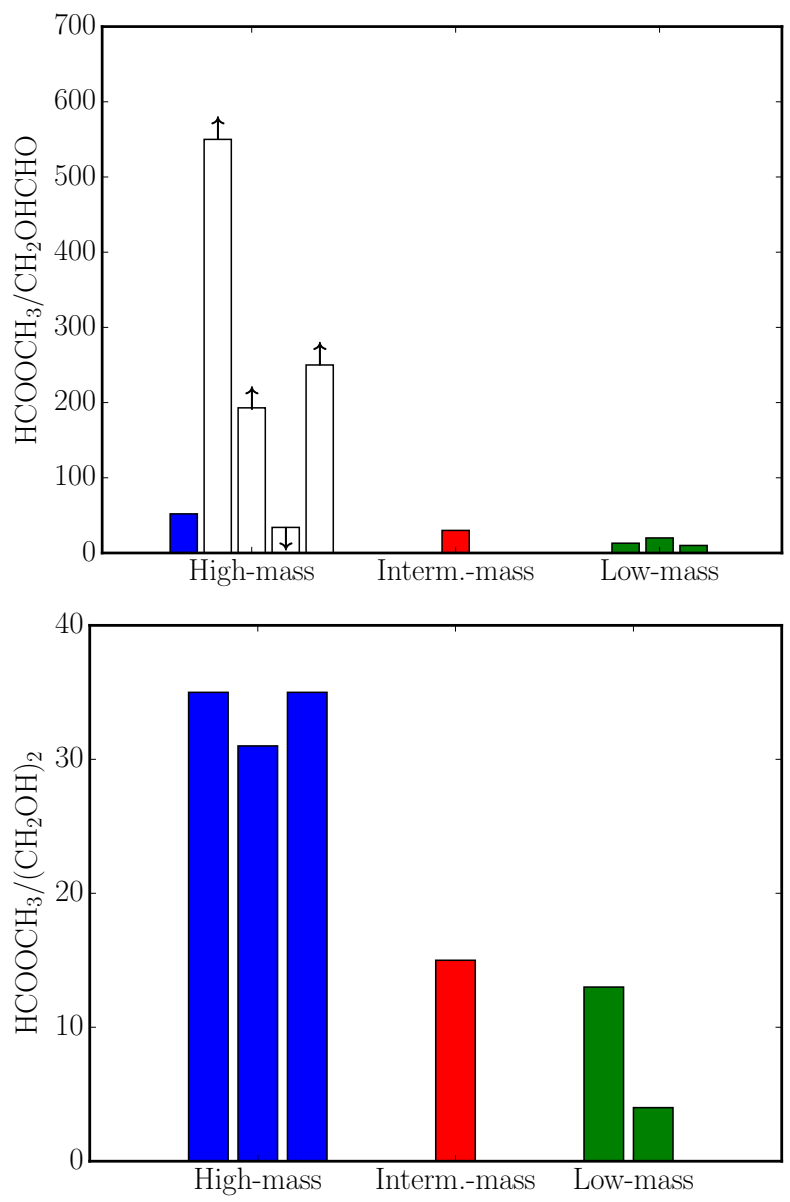

Fig. 3. Schematic bar plot of $\mathrm{HCOOCH}_{3} / \mathrm{CH}_{2} \mathrm{OHCHO}$ (top) and $\mathrm{HCOOCH}_{3} /\left(\mathrm{CH}_{2} \mathrm{OH}\right)_{2}$ (bottom) against $L_{\text {bol }}$. The sources from Table 4 have been plotted in descending order of luminosity from left to right on the $x$-axis, but not to scale, and the sources have been grouped into highmass sources (blue), intermediate-mass protostar (red) and low-mass protostars (green). The white bars for four of the high-mass sources are upper or lower levels, which is indicated by the direction of the arrow. The luminosity for the top plot spans from Sgr B2(N) with $L_{\text {bol }}=10^{7} L_{\odot}$ to IRAS NGC $13334 \mathrm{~A}$ with $L_{\text {bol }}=7.7 L_{\odot}$, while it spans from W51/e2 with $L_{\text {bol }}=4.7 \times 10^{6} L_{\odot}$ to IRAS NGC 13334 A with $L_{\text {bol }}=20 L_{\odot}$ in the bottom plot.

where the $\left(\mathrm{CH}_{2} \mathrm{OH}\right)_{2}$ abundance actually drops two to three magnitudes when the initial $\mathrm{CH}_{3} \mathrm{OH}$ ice-composition in their model is reduced by a factor of 10 . However, to date there is no observational evidence that the ice contents on the grains vary in any statistically significant way from high-mass protostars to low-mass protostars (Öberg et al. 2011).

Until recently it has been speculated that a high $\left(\mathrm{CH}_{2} \mathrm{OH}\right)_{2} / \mathrm{CH}_{2} \mathrm{OHCHO}$ ratio is a specific property of comets (Biver et al. 2014). But since Coutens et al. (2015) report a value of around five for a low-mass protostar, and both we and Brouillet et al. (2015), report lower limits of >6-16 for highmass sources, then a $\left(\mathrm{CH}_{2} \mathrm{OH}\right)_{2} / \mathrm{CH}_{2} \mathrm{OHCHO}$ ratio greater than three can be expected to be observed in other sources as well.

\section{Conclusions}

In summary, we have tentatively detected $\left(\mathrm{CH}_{2} \mathrm{OH}\right)_{2}$ in $\mathrm{G} 34.3+0.2$ for the first time, and our tentative detection in W51/e 2 confirms the previous marginally detection by Kalenskii \& Johansson (2010). In addition, we derived upper limits for the column density of $\mathrm{CH}_{2} \mathrm{OHCHO}$ emission in both sources. From these data we determined the relative abundance ratios of $\left(\mathrm{CH}_{2} \mathrm{OH}\right)_{2}, \mathrm{HCOOCH}_{3}$, and $\mathrm{CH}_{2} \mathrm{OHCHO}$ and compared these to measurements from the literature covering a wide range of source environments and luminosities. The data show what appears to be a correlation between source luminosity and $\mathrm{HCOOCH}_{3} /\left(\mathrm{CH}_{2} \mathrm{OH}\right)_{2}$, as well as $\mathrm{HCOOCH}_{3} / \mathrm{CH}_{2} \mathrm{OHCHO}$. This apparent correlation is proposed to be a consequence of the relative time scales each source spends at different temperature ranges in their evolution. Using the upper limit for the column density of $\mathrm{CH}_{2} \mathrm{OHCHO}$ gives a lower limit for $\left(\mathrm{CH}_{2} \mathrm{OH}\right)_{2} / \mathrm{CH}_{2} \mathrm{OHCHO}$ of $>16$ and $>6$ for $\mathrm{W} 51 / 2$ and $\mathrm{G} 34.3+0.2$, respectively. These results, together with an upper limit of $>12$ for Orion-KL (Brouillet et al. 2015) and $\left(\mathrm{CH}_{2} \mathrm{OH}\right)_{2} / \mathrm{CH}_{2} \mathrm{OHCHO}=5$ for IRAS NGC $13332 \mathrm{~A}$ (Coutens et al. 2015), shows that one can expect to find a high $\left(\mathrm{CH}_{2} \mathrm{OH}\right)_{2} / \mathrm{CH}_{2} \mathrm{OHCHO}$ abundance ratio in multiple types of environments.

Additional systematic surveys of these and other relevant molecules in additional sources, as well as more model and laboratory work, is needed to fully constrain the formation pathway of complex molecules. In particular, the Atacama Large Millimeter/submillimeter Array (ALMA) shows great potential for successfully revealing the formation processes with its high sensitivity and resolution, making it possible to map the relative spatial distributions of these sources.

Acknowledgements. We would like to thank the referee, Malcolm Walmsley, for his help improving the paper. The research of J.M.L. and J.K.J. was supported by a Junior Group Leader Fellowship from the Lundbeck Foundation to J.K.J., - as well as the Centre for Star and Planet Formation funded by the Danish National Research Foundation. C.F. acknowledges support from the National Science Foundation under grant 1008800.

\section{References}

Aikawa, Y., Wakelam, V., Garrod, R. T., \& Herbst, E. 2008, ApJ, 674, 984 Beltrán, M. T., Codella, C., Viti, S., Neri, R., \& Cesaroni, R. 2009, ApJ, 690, L93

Bisschop, S. E., Jørgensen, J. K., van Dishoeck, E. F., \& de Wachter, E. B. M. 2007, A\&A, 465, 913

Biver, N., Bockelée-Morvan, D., Debout, V., et al. 2014, A\&A, 566, L5

Blake, G. A., Sutton, E. C., Masson, C. R., \& Phillips, T. G. 1987, ApJ, 315, 621

Bockelée-Morvan, D., Lis, D. C., Wink, J. E., et al. 2000, A\&A, 353, 1101

Brouillet, N., Despois, D., Lu, X.-H., et al. 2015, A\&A, 576, A129

Carroll, P. B., Drouin, B. J., \& Widicus Weaver, S. L. 2010, ApJ, 723, 845

Charnley, S. B., Tielens, A. G. G. M., \& Millar, T. J. 1992, ApJ, 399, L71

Christen, D., Coudert, L. H., Suenram, R. D., \& Lovas, F. J. 1995, J. Mol. Spectr., 172,57

Christen, D., \& Müller, H. S. P. 2003, Phys. Chem. Chem. Phys., 5, 3600

Coutens, A., Persson, M. V., Jørgensen, J. K., Wampfler, S. F., \& Lykke, J. M. 2015, A\&A, 576, A5

Crockett, N. R., Bergin, E. A., Neill, J. L., et al. 2014, ApJ, 781, 114

Crovisier, J., Bockelée-Morvan, D., Biver, N., et al. 2004a, A\&A, 418, L35

Crovisier, J., Bockelée-Morvan, D., Colom, P., et al. 2004b, A\&A, 418, 1141

Demyk, K., Wlodarczak, G., \& Carvajal, M. 2008, A\&A, 489, 589

Favre, C., Despois, D., Brouillet, N., et al. 2011, A\&A, 532, A32

Favre, C., Carvajal, M., Field, D., et al. 2014, ApJS, 215, 25

Fuente, A., Cernicharo, J., Caselli, P., et al. 2014, A\&A, 568, A65

Garrod, R. T., Weaver, S. L. W., \& Herbst, E. 2008, ApJ, 682, 283

Geppert, W. D., Hamberg, M., Thomas, R. D., et al. 2006, Faraday Discussions, 133,177

Goldsmith, P. F., \& Langer, W. D. 1999, ApJ, 517, 209

Goldsmith, P. F., Lis, D. C., Hills, R., \& Lasenby, J. 1990, ApJ, 350, 186

Halfen, D. T., Apponi, A. J., Woolf, N., Polt, R., \& Ziurys, L. M. 2006, ApJ, 639, 237

Herbst, E., \& van Dishoeck, E. F. 2009, ARA\&A, 47, 427

Hollis, J. M., Lovas, F. J., \& Jewell, P. R. 2000, ApJ, 540, L107

Hollis, J. M., Vogel, S. N., Snyder, L. E., Jewell, P. R., \& Lovas, F. J. 2001, ApJ, 554, L81 
J. M. Lykke et al.: Tentative detection of ethylene glycol toward W51/e2 and G34.3+0.2

Hollis, J. M., Lovas, F. J., Jewell, P. R., \& Coudert, L. H. 2002, ApJ, 571, L59

Hollis, J. M., Jewell, P. R., Lovas, F. J., \& Remijan, A. 2004, ApJ, 613, L45

Ilyushin, V., Kryvda, A., \& Alekseev, E. 2009, J. Mol. Spectr., 255, 32

Jørgensen, J. K., van Dishoeck, E. F., Visser, R., et al. 2009, A\&A, 507, 861

Jørgensen, J. K., Favre, C., Bisschop, S. E., et al. 2012, ApJ, 757, L4

Kalenskii, S. V., \& Johansson, L. E. B. 2010, Astron. Rep., 54, 1084

Kurtz, S., Cesaroni, R., Churchwell, E., Hofner, P., \& Walmsley, C. M. 2000, Protostars and Planets IV, 299

Maury, A. J., Belloche, A., André, P., et al. 2014, A\&A, 563, L2

Millar, T. J., Herbst, E., \& Charnley, S. B. 1991, ApJ, 369, 147

Müller, H. S. P., Thorwirth, S., Roth, D. A., \& Winnewisser, G. 2001, A\&A, 370, L49

Müller, H. S. P., Schlöder, F., Stutzki, J., \& Winnewisser, G. 2005, J. Mol. Str., 742,215

Öberg, K. I., Garrod, R. T., van Dishoeck, E. F., \& Linnartz, H. 2009, A\&A, 504, 891
Öberg, K. I., Boogert, A. C. A., Pontoppidan, K. M., et al. 2011, ApJ, 740, 109 Pickett, H. M., Poynter, I. R. L., Cohen, E. A., et al. 1998, J. Quant. Spectr. Radiat. Trans., 60, 883

Remijan, A., Snyder, L. E., Friedel, D. N., Liu, S.-Y., \& Shah, R. Y. 2003, ApJ, 590,314

Requena-Torres, M. A., Martín-Pintado, J., Martín, S., \& Morris, M. R. 2008, ApJ, 672, 352

Sato, M., Reid, M. J., Brunthaler, A., \& Menten, K. M. 2010, ApJ, 720, 1055

Schöier, F. L., Jørgensen, J. K., van Dishoeck, E. F., \& Blake, G. A. 2002, A\&A, 390, 1001

Taquet, V., López-Sepulcre, A., Ceccarelli, C., et al. 2015, ApJ, 804, 81

Urquhart, J. S., Figura, C. C., Moore, T. J. T., et al. 2014, MNRAS, 437, 1791

van Dishoeck, E. F., Kristensen, L. E., Benz, A. O., et al. 2011, PASP, 123, 138

Viti, S., Collings, M. P., Dever, J. W., McCoustra, M. R. S., \& Williams, D. A. 2004, MNRAS, 354, 1141

Zhang, Q., Ho, P. T. P., \& Ohashi, N. 1998, ApJ, 494, 636 


\section{Appendix A: Reference model}

Table A.1. Column densities of species in our reference model.

\begin{tabular}{lcc}
\hline \hline Molecule & $\begin{array}{c}\mathrm{G} 34.3+0.2 \\
{\left[\mathrm{~cm}^{-2}\right]}\end{array}$ & $\begin{array}{c}\text { W51/e2 } \\
{\left[\mathrm{cm}^{-2}\right]}\end{array}$ \\
\hline $\mathrm{CH}_{3} \mathrm{OCH}$ & $4 \times 10^{16}$ & $3 \times 10^{17}$ \\
$\mathrm{HCOOH} \mathrm{t}$ & $1 \times 10^{15}$ & $1 \times 10^{16}$ \\
$\mathrm{CH}_{3} \mathrm{CHO}$ & $2 \times 10^{15}$ & $1 \times 10^{16}$ \\
$\mathrm{CH}_{3} \mathrm{OH}$ & $1 \times 10^{17}$ & $3 \times 10^{18}$ \\
$\mathrm{C}_{2} \mathrm{H}_{5} \mathrm{OH}$ & $1 \times 10^{16}$ & $1 \times 10^{17}$ \\
$\mathrm{CH}_{3} \mathrm{CN}$ & $2 \times 10^{15}$ & $6 \times 10^{16}$ \\
\hline
\end{tabular}

Notes. Estimated column densities of other relevant organic species. These values are used to create synthetic spectra, which serves as a reference model when identifying lines.

\section{Appendix B: Observed and synthetic spectra}
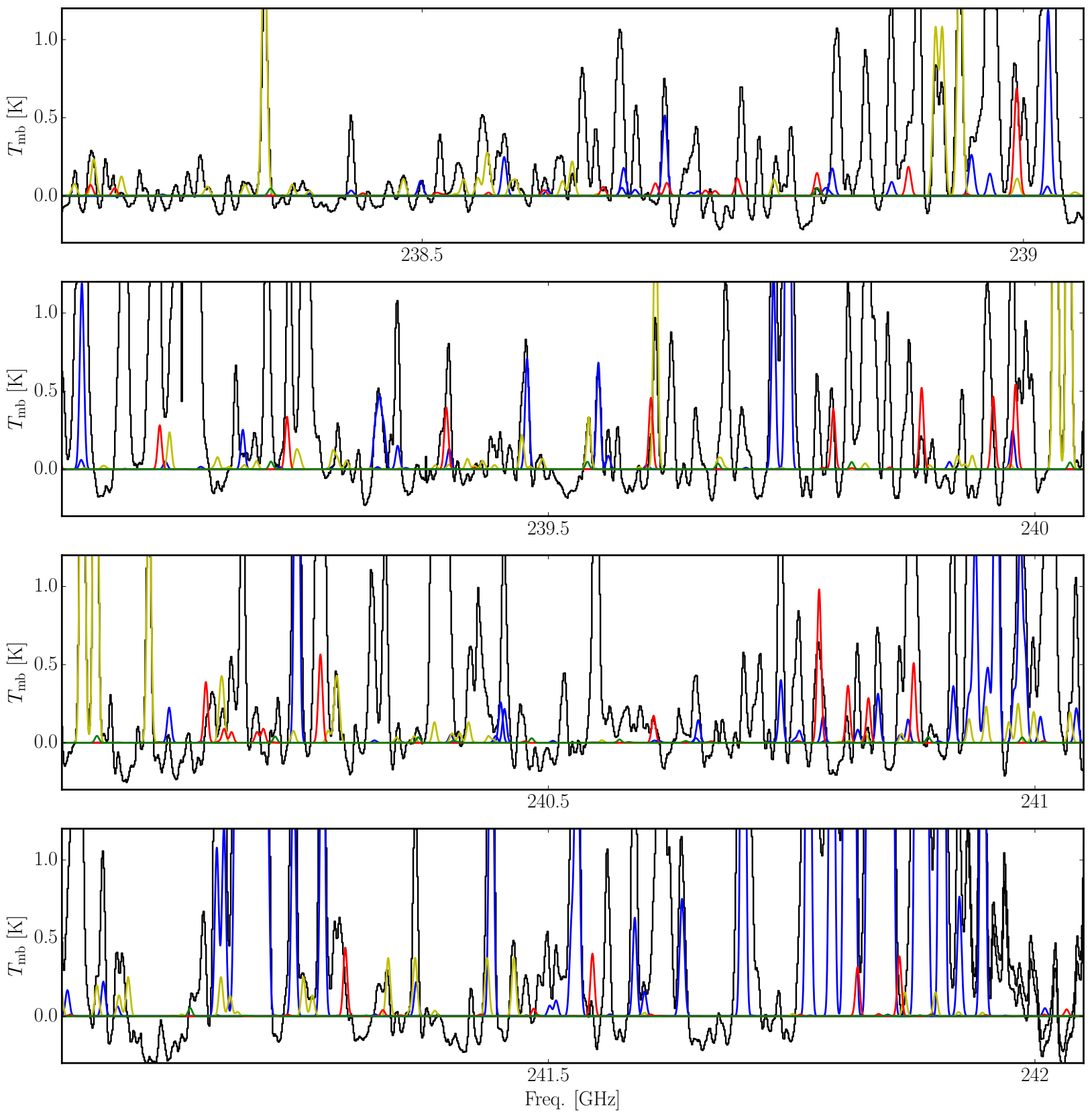

Fig. B.1. Synthetic spectra (red: $\left(\mathrm{CH}_{2} \mathrm{OH}\right)_{2}$, yellow: $\mathrm{HCOOCH}_{3}$, green: $\mathrm{CH}_{2} \mathrm{OHCHO}$, blue: the molecules listed in Table A.1) on top of observed spectrum (black) at $1 \mathrm{~mm}$ for $\mathrm{W} 51 / \mathrm{e} 2$ in the frequency range $\sim 238-242 \mathrm{GHz}$. 
J. M. Lykke et al.: Tentative detection of ethylene glycol toward W51/e2 and G34.3+0.2
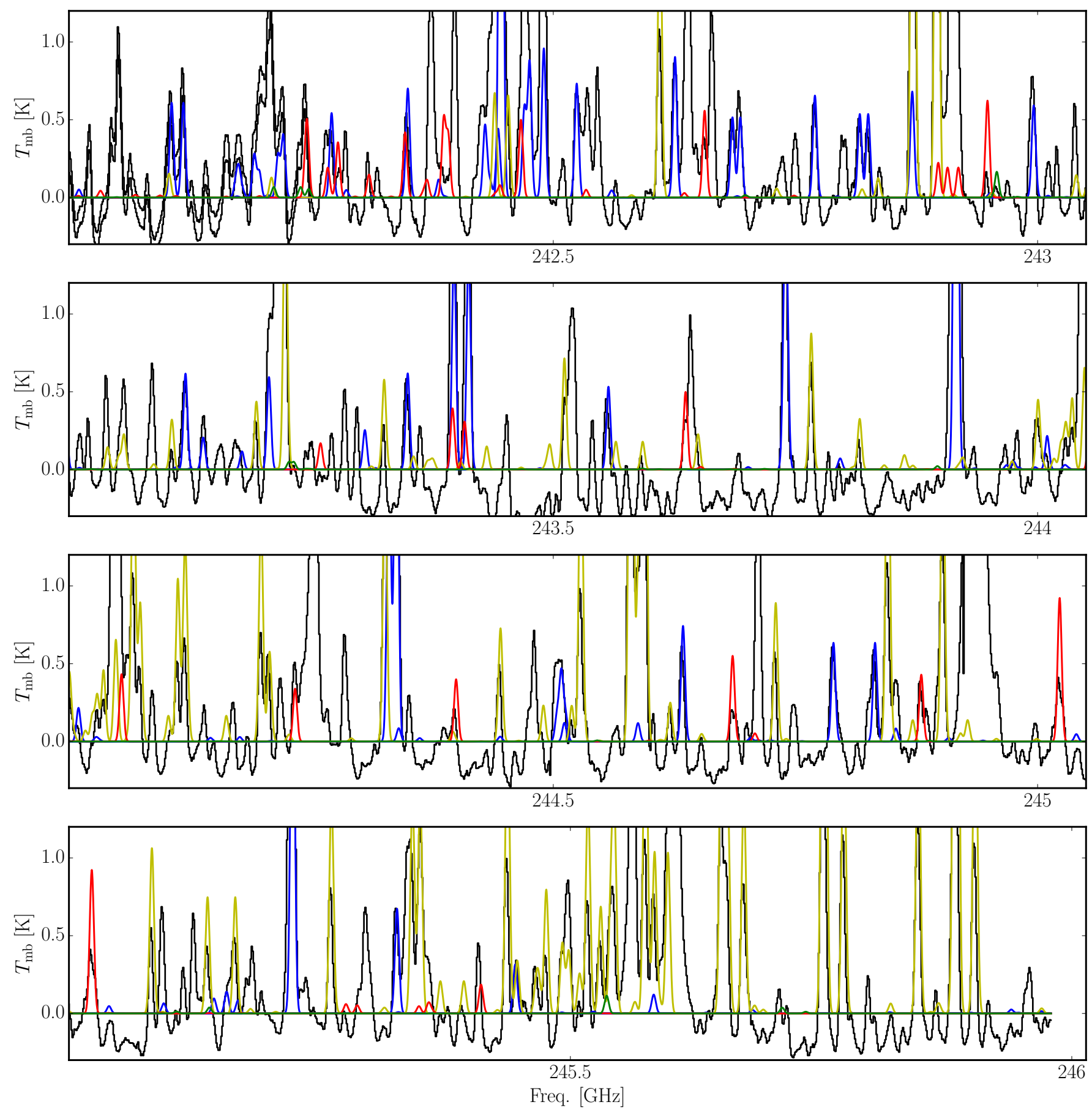

Fig. B.2. Same as Fig. B.1 but for 242-246 GHz. 


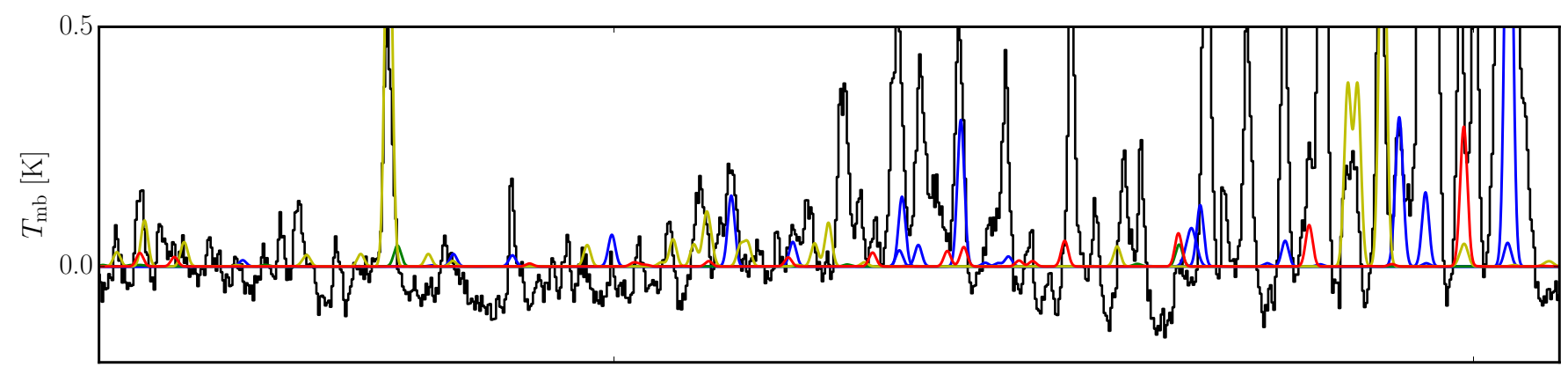

238.5

239
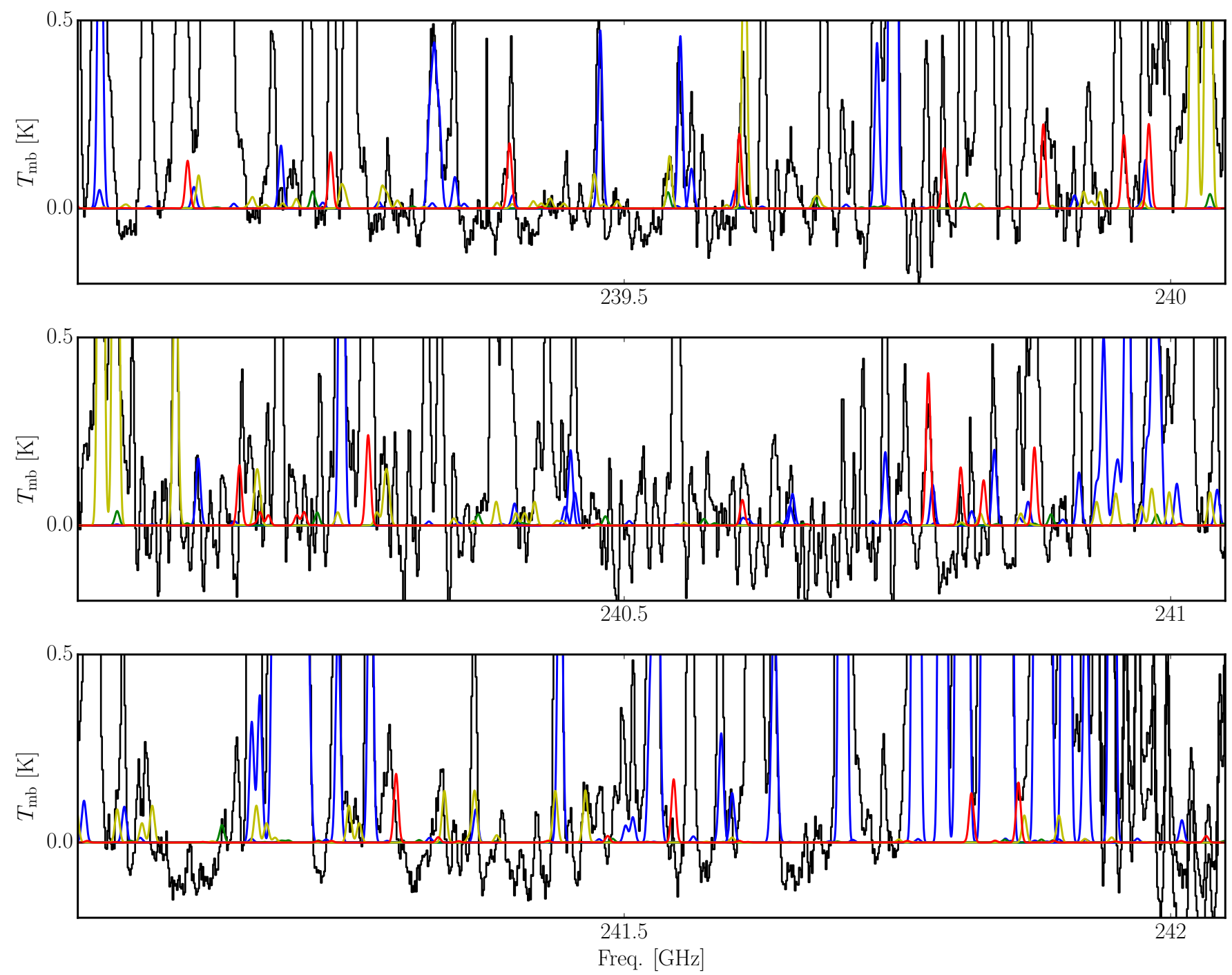

Fig. B.3. Synthetic spectra (red: $\left(\mathrm{CH}_{2} \mathrm{OH}\right)_{2}$, yellow: $\mathrm{HCOOCH}_{3}$, green: $\mathrm{CH}_{2} \mathrm{OHCHO}$, blue: the molecules listed in Table A.1) on top of observed spectrum (black) at $1 \mathrm{~mm}$ for G34.3+0.2 in the frequency range $\sim 238-242 \mathrm{GHz}$. 
J. M. Lykke et al.: Tentative detection of ethylene glycol toward W51/e2 and G34.3+0.2
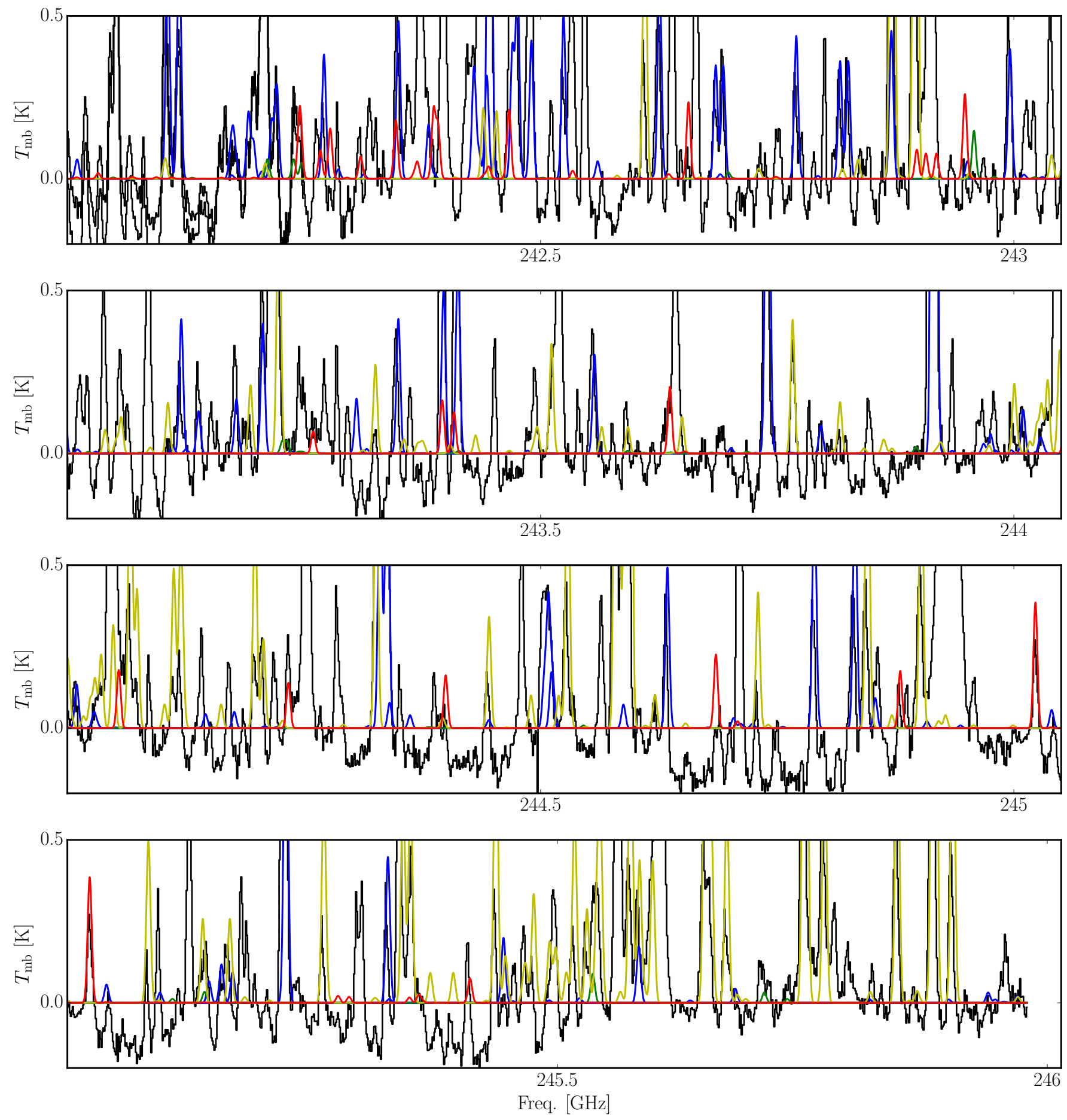

Fig. B.4. Same as for Fig. B.3 but for $\sim 242-246 \mathrm{GHz}$. 

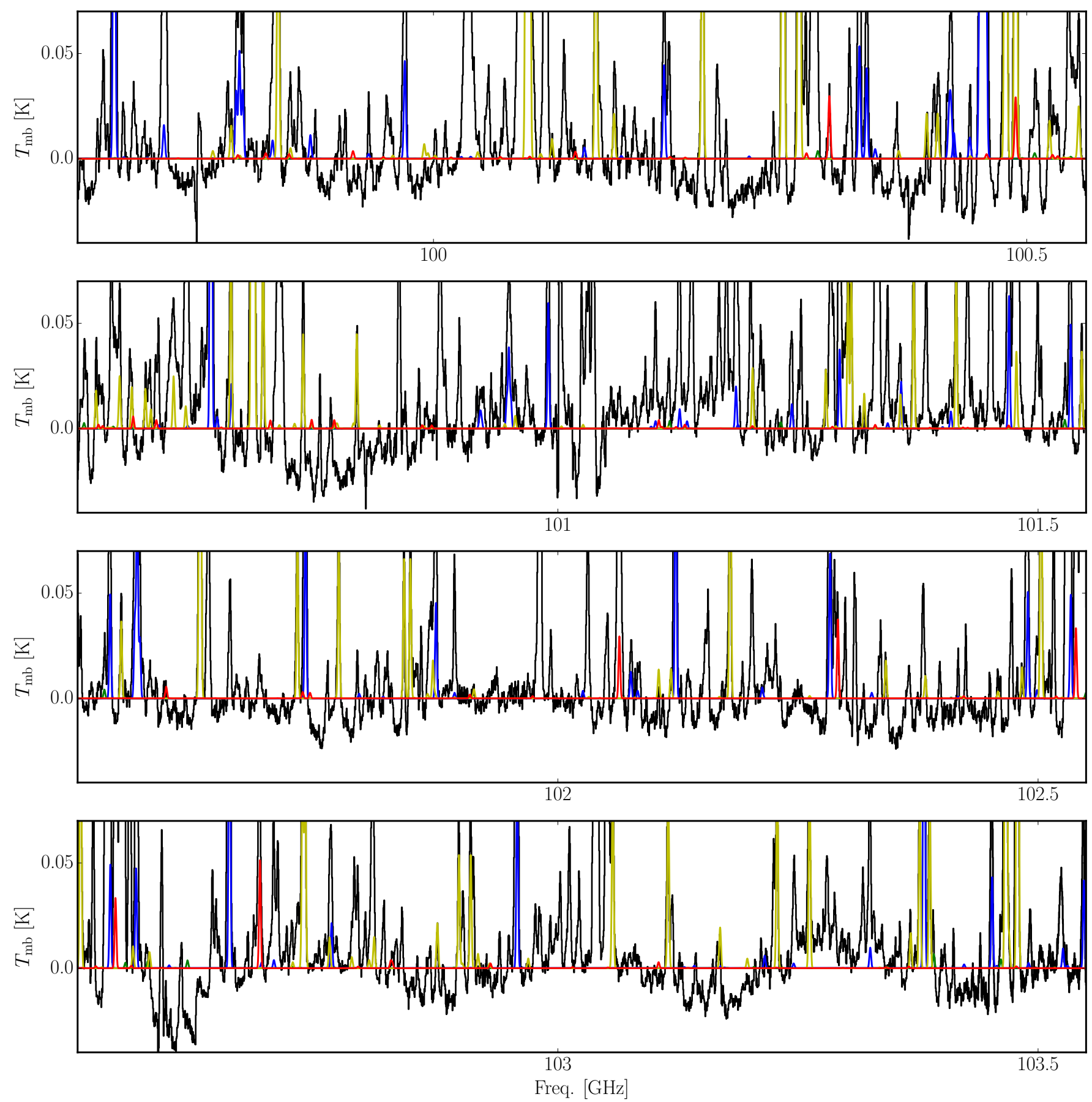

Fig. B.5. Synthetic spectra (red: $\left(\mathrm{CH}_{2} \mathrm{OH}\right)_{2}$, yellow: $\mathrm{HCOOCH}_{3}$, green: $\mathrm{CH}_{2} \mathrm{OHCHO}$, blue: the molecules listed in Table A.1) on top of observed spectrum (black) at $3 \mathrm{~mm}$ for $\mathrm{W} 51 / \mathrm{e} 2$ in the frequency range $\sim 100-103 \mathrm{GHz}$. 
J. M. Lykke et al.: Tentative detection of ethylene glycol toward W51/e2 and G34.3+0.2
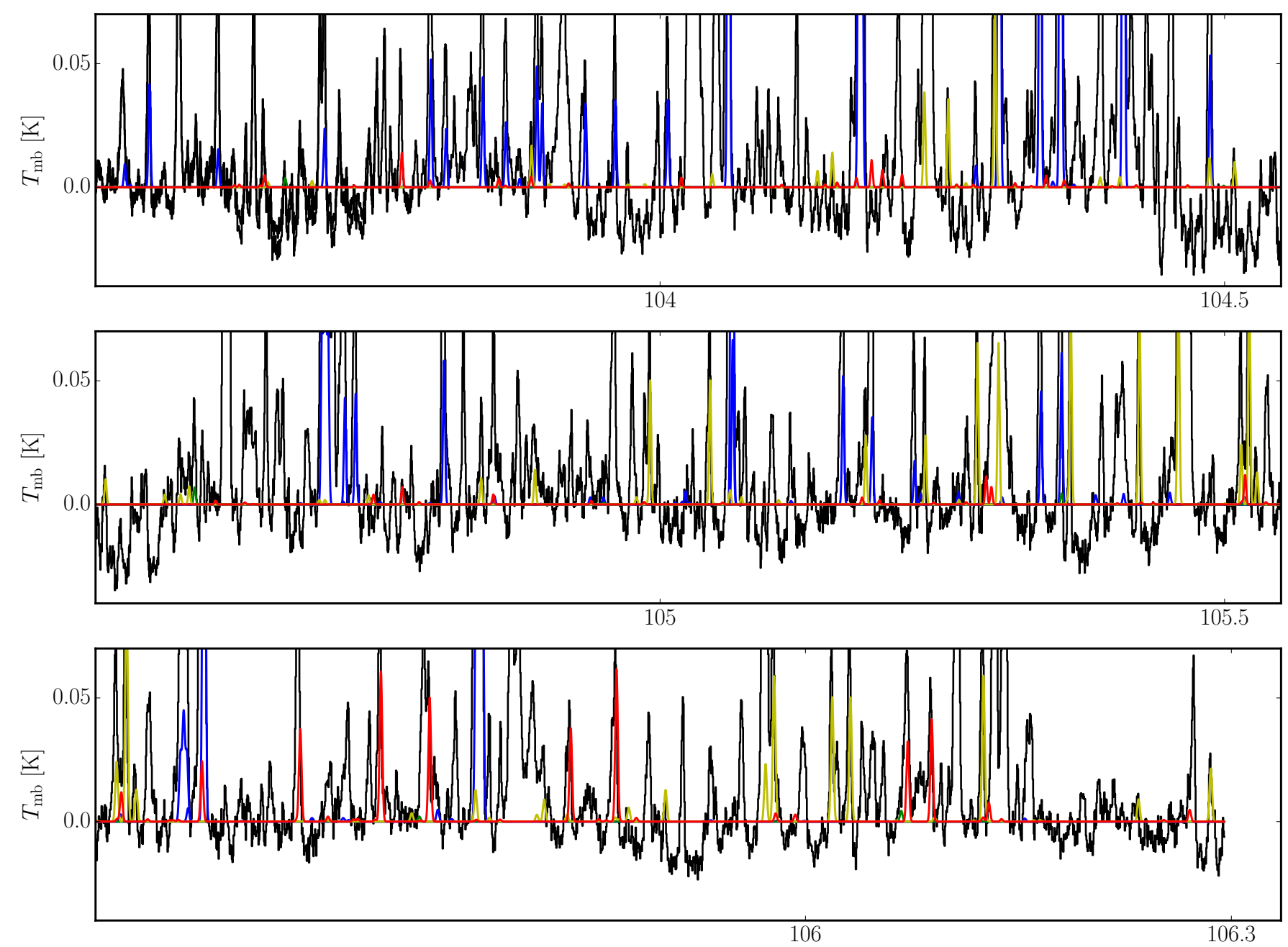

Fig. B.6. Same as for Fig. B.5 but for $\sim 103-106 \mathrm{GHz}$. 

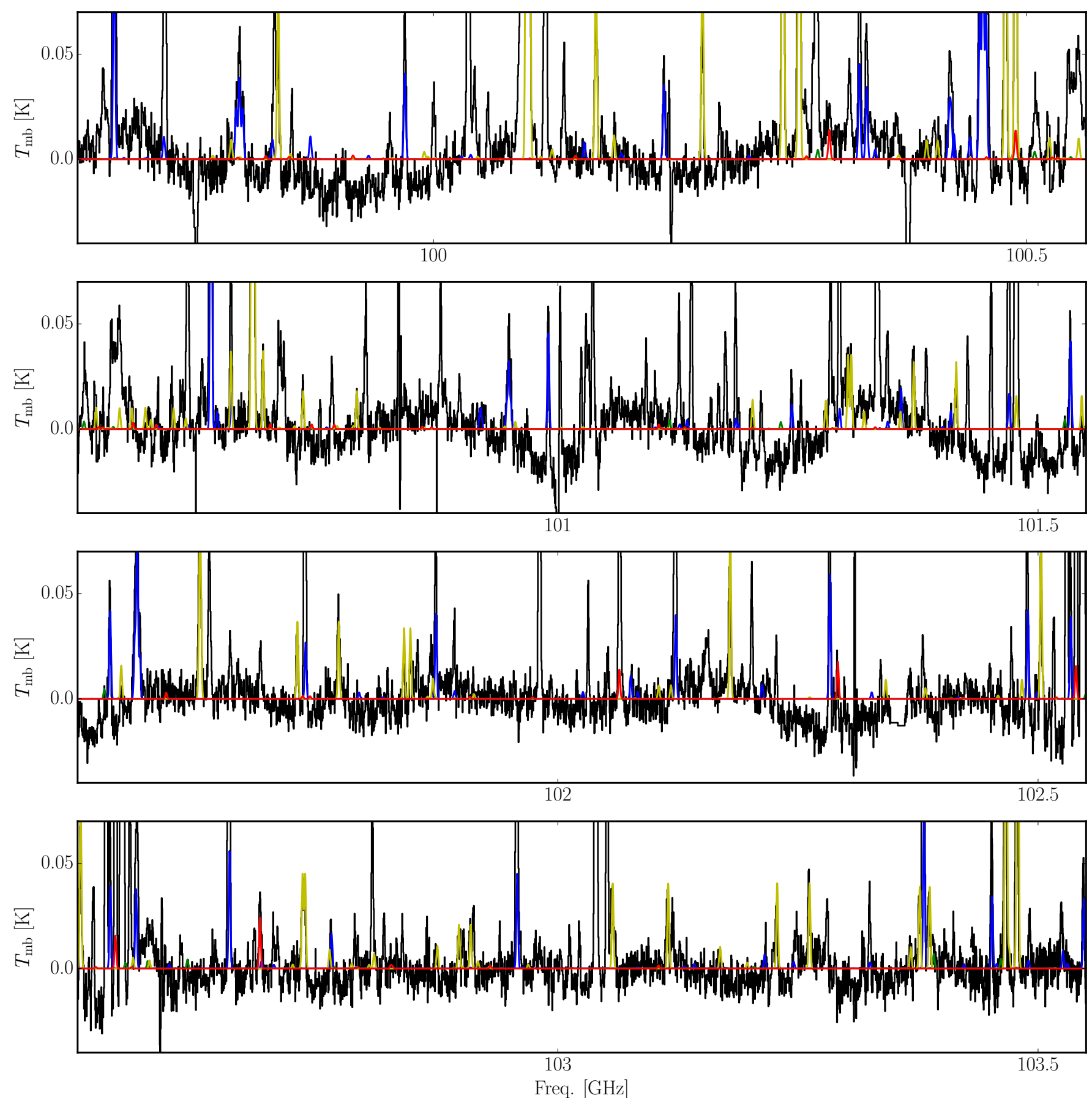

Fig. B.7. Synthetic spectra (red: $\left(\mathrm{CH}_{2} \mathrm{OH}\right)_{2}$, yellow: $\mathrm{HCOOCH}_{3}$, green: $\mathrm{CH}_{2} \mathrm{OHCHO}$, blue: the molecules listed in Table A.1) on top of observed spectrum (black) at $3 \mathrm{~mm}$ for G34.3+0.2 in the frequency range $\sim 100-103 \mathrm{GHz}$. 
J. M. Lykke et al.: Tentative detection of ethylene glycol toward W51/e2 and G34.3+0.2

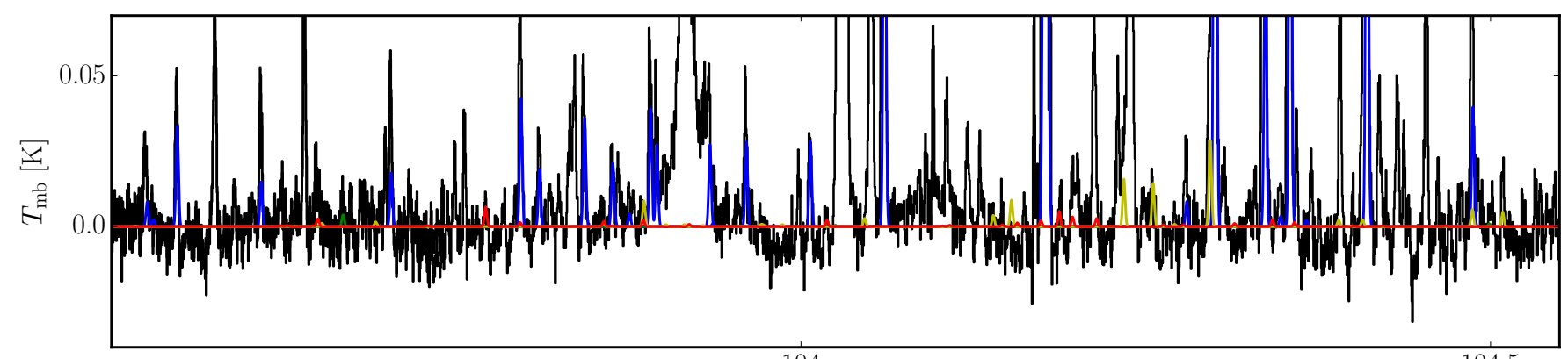

104

104.5
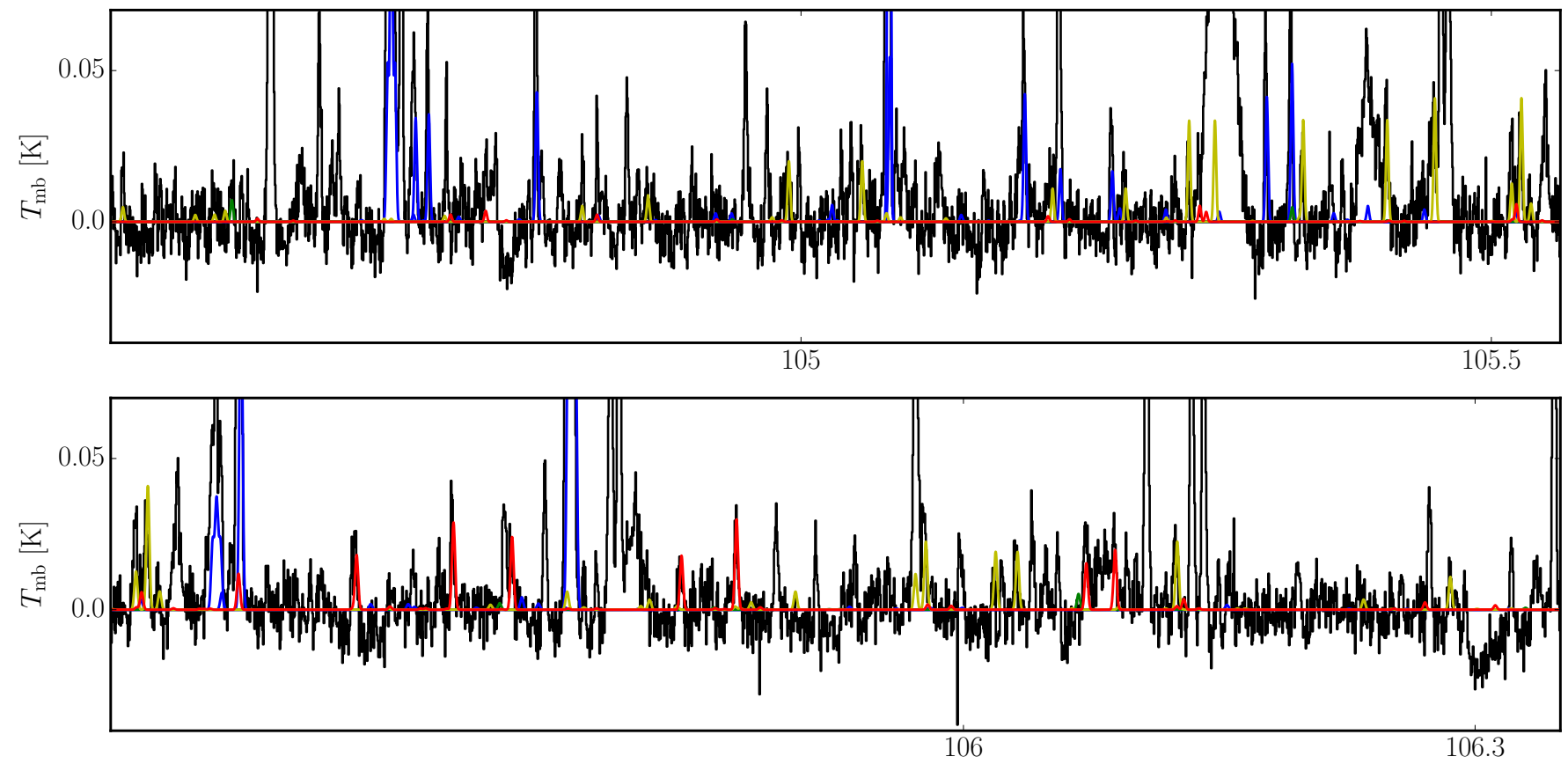

Fig. B.8. Same as for Fig. B.7 but for $~ 103-106 \mathrm{GHz}$. 